NBER WORKING PAPER SERIES

\title{
UNINTENDED CONSEQUENCES OF LOLR FACILITIES: THE CASE OF ILLIQUID LEVERAGE
}

\author{
Viral V. Acharya \\ Bruce Tuckman \\ Working Paper 19773 \\ http://www.nber.org/papers/w19773
NATIONAL BUREAU OF ECONOMIC RESEARCH
1050 Massachusetts Avenue
Cambridge, MA 02138 \\ December 2013
}

This paper was prepared for the IMF Economic Review Conference in Honor of Stanley Fischer. We are grateful to Pierre-Olivier Gourinchas and Ayhan Kose (editors), Ricardo Caballero (discussant), three anonymous referees, and participants at the International Monetary Fund's 14th Jacques Polak Conference in honor of Stanley Fischer on November 7-8, 2013, for helpful comments. We thank Katherine Waldock for outstanding research assistance. All errors remain our own. The views expressed herein are those of the authors and do not necessarily reflect the views of the National Bureau of Economic Research.

At least one co-author has disclosed a financial relationship of potential relevance for this research. Further information is available online at http://www.nber.org/papers/w19773.ack

NBER working papers are circulated for discussion and comment purposes. They have not been peerreviewed or been subject to the review by the NBER Board of Directors that accompanies official NBER publications.

(C) 2013 by Viral V. Acharya and Bruce Tuckman. All rights reserved. Short sections of text, not to exceed two paragraphs, may be quoted without explicit permission provided that full credit, including (C) notice, is given to the source. 
Unintended Consequences of LOLR Facilities: The Case of Illiquid Leverage

Viral V. Acharya and Bruce Tuckman

NBER Working Paper No. 19773

December 2013

JEL No. D62,E58,G01,G21,G24,G28

\begin{abstract}
$\underline{\text { ABSTRACT }}$
While the direct effect of lender-of-last-resort (LOLR) facilities is to forestall the default of financial firms that lose funding liquidity, an indirect effect is to allow these firms to minimize deleveraging sales of illiquid assets. This unintended consequence of LOLR facilities manifests itself as excess illiquid leverage in the financial sector, can make future liquidity shortfalls more likely, and can lead to an increase in default risks. Furthermore, this increase in default risk can occur despite the fact that the combination of LOLR facilities and reduced asset sales raises the prices of illiquid assets.
\end{abstract}

The behavior of U.S. broker-dealers during the crisis of 2007-2009 is consistent with the unintended consequence just described. In particular, given the Federal Reserve's LOLR facilities, broker-dealers could afford to try to wait out the crisis. While they did reduce traditional measures of leverage to varying degrees, they failed to reduce sufficiently their illiquid leverage, which contributed to their failures or near failures.

Several mechanisms that might address this unintended consequence of LOLR facili-ties are explored: condition LOLR access and terms on the financial health of borrowers; condition LOLR access and terms on asset sales and deleveraging; and, especially, in-stead of supporting troubled financial firms, open LOLR facilities to financially sound, potential buyers of illiquid assets.

\author{
Viral V. Acharya \\ Stern School of Business \\ New York University \\ 44 West 4th Street, Suite 9-84 \\ New York, NY 10012 \\ and CEPR \\ and also NBER \\ vacharya@stern.nyu.edu \\ Bruce Tuckman \\ 44 West 4th St \\ New York \\ NY 10012, USA \\ btuckman@stern.nyu.edu
}




\section{Introduction}

Since 2007, central banks worldwide have offered lender-of-last-resort (LOLR) facilities to private financial institutions in unprecedented scope and scale. These facilities provide funding against relatively illiquid assets in times of market stress so as to prevent downward spirals in which balance sheet weaknesses beget asset fire sales, which beget further balance sheet weaknesses, etc., until the financial sector's ruin devastates the real economy.

LOLR facilities are hardly a panacea, however. The ex-ante moral hazard of providing such facilities in a crisis is well and widely recognized: financial institutions, knowing that authorities will offer liquidity in a crisis, take too much liquidity risk from a societal perspective. In addition, despite the ex-post societal benefits of LOLR facilities, the sense in which these facilities bail out financial institutions generates considerable political fallout.

This subject of this paper is a less recognized moral hazard of LOLR facilities, which occurs when these facilities are in operation. Consider the following exchange at Merrill Lynch's earnings call from the second quarter of 2008. Meredith Whitney, a well-known analyst at Oppenheimer, asked John Thain, Chairman and CEO of Merrill Lynch, whether the firm could put its balance sheet problems behind it by "hitting whatever cash bid... is out there" for its troubled assets. Mr. Thain responded as follows:

We have not simply liquidated stuff at any price we could get. At some point some of the return profiles that people want... you would not want us to sell the assets. We will continue to sell assets but in a way that makes sense from generating returns to our shareholders. ${ }^{1}$

Out of context, this response seems perfectly reasonable: the CEO of a financial institution is promising to conduct asset sales so as to maximize shareholder returns. In context, however, Mr. Thain's statement is quite remarkable. Following the collapse of Bear Stearns in mid-March 2008, the Federal Reserve established unprecedented LOLR liquidity facilities, namely the Term Securities Lending Facility (TSLF) and the Primary Dealer Credit Facility (PDCF), to ease the precarious funding conditions that were perceived to threaten the very survival of broker-dealers.

\footnotetext{
${ }^{1}$ Merrill Lynch, Q2 Earnings Call, July 17, 2008
} 
It would not be unreasonable to expect broker-dealers to use the respite provided by these facilities to sell troubled assets gradually, i.e., to strengthen their balance sheets without dumping assets in an individually and systemically harmful manner. Instead, while the Federal Reserve, and by extension the U.S. taxpayer, stood ready to fund assets and assume whatever risks that entailed, the CEO of a beneficiary of these LOLR facilities proclaimed that asset sales would be conducted so as to generate returns for shareholders. Worse yet, Merrill Lynch's delay in deleveraging its balance sheet, made possible at least in part by LOLR facilities, was a factor contributing to its demise as an independent firm in September 2008, a mere two months after Mr. Thain's remarks.

The case of Merrill Lynch in July 2008 is only a single instance of a much wider phenomenon. Whether considering the Federal Reserve's set of LOLR programs in the U.S. during the '07-'09 financial crisis, including traditional discount window lending, the Bank of Japan's Funds Supplying Operation in '09-'10, or the European Central Bank's (ECB's) recent Long-Term Refinancing Operations (LTRO), there is a concern that private financial institutions take advantage of central bank funding programs by dragging their feet on deleveraging. With this motivation, this paper argues, both theoretically and through a case study, that LOLR facilities as currently designed can have the unintended consequence of reducing the extent to which financial firms delever and, therefore, can actually increase these firms' risks of default.

To establish its theoretical results, this paper constructs a model designed to capture the plight of many banks and investment banks during the most recent crisis. In particular, a representative bank has borrowed short term to fund the purchase of long-term and relatively illiquid assets. Then, due to market stress, these assets sell for less than their fundamental values and have become difficult to finance. ${ }^{2}$ The bank, consequently, needs to delever, i.e., to sell some of its assets, despite their being undervalued, so that the firm has enough funds on hand to redeem any maturing debt that cannot be rolled over.

The central bank steps into this setting by offering to fund the illiquid asset at better terms than those offered by private funding markets. The direct effect of such an LOLR facility, the

\footnotetext{
${ }^{2}$ Broker-dealers normally rely on private markets to finance their positions, but these markets became severely impaired in early 2008. Lenders of funds through repurchase agreements became increasingly cautious, worrying both about the liquidation value of collateral and about the credit risk of counterparties. These lenders reacted by increasing haircuts - reducing the cash they were willing to lend against a given amount of collateral - and by refusing to lend at all against certain types of collateral. See, for example, Copeland, Martin and Walker (2011), Gorton and Metrick (2012), and Krishnamurthy, Nagel, and Orlov (2012).
} 
"liquidity insurance effect," is to forestall the default of a bank in all but the worst stress conditions. The indirect effect, however, the "moral hazard effect," is to give the bank leeway to reduce deleveraging sales of illiquid assets. In the simplest version of the model, where the price of the illiquid asset is exogenous, the moral hazard effect not only exists, but dominates the liquidity insurance effect so that the LOLR facility actually increases the risk of a bank default. Furthermore, the moral hazard effect can be particulary powerful for the weakest or most highly-levered banks.

The paper then considers a version of the model to account for the fact that the illiquid asset price is actually determined endogenously, which has implications for any equilibrium conclusions about the effects of LOLR facilities. More specifically, the model introduces a representative buyer of the asset as a stand in for those less leveraged banks and investment banks, hedge funds, pension funds, insurance companies, asset managers, etc., who are able to purchase distressed assets opportunistically in a crisis. The bank's supply curve, or willingness to sell the illiquid asset, together with the buyer's demand curve, or willingness to buy the illiquid asset, combine to determine the asset's equilibrium price. Analytic results are more elusive in this model, but, restricting equilibria to those in which LOLR facilities increase the price of the illiquid asset, numerical analysis shows that the qualitative results of the simpler model obtain. In particular, the moral hazard effect still exists and, for certain ranges of LOLR funding terms, the LOLR facility increases the bank's probability of default.

The version of the model with an endogenously-determined asset price generates a further result that has particular relevance for public policy. Giving the buyer access to the LOLR facility, instead of the troubled bank, results in an equilibrium with a higher illiquid asset price, a higher degree of bank deleveraging, and a lower probability of bank default. In other words, a buyer-access LOLR facility may overcome the moral hazard that is the subject of this paper.

The case study section of the paper shows that the behavior of U.S. broker-dealers during the crisis of 2007-2009 is consistent with the model and its results. The section starts with a primer on broker-dealer balance sheets and introduces "illiquid inventory leverage," a new measure of a financial firm's risk that is more consistent with market concerns during the crisis than are the more traditional measures of leverage. The paper then documents the deleveraging behavior of broker-dealers after the establishment of the TSLF and PDCF in mid-March 2008. The weakest two broker-dealers, namely Lehman Brothers and Merrill Lynch, did reduce broader measures 
of leverage, but did little to reduce their most important exposures, i.e., their risks to illiquid assets, and failed in September 2008. The strongest two broker-dealers, namely Morgan Stanley and Goldman Sachs, did reduce illiquid leverage substantially in response to the the fall of Bear Stearns, but then took a break from deleveraging in the third quarter of that year. In the market turmoil following the bankruptcy of Lehman Brothers, however, Morgan Stanley and Goldman Sachs resumed their reduction of illiquid asset inventory, but market conditions at that point limited what they could accomplish.

The facts of broker-dealer deleveraging are consistent with the model of the paper: during a crisis, with the security of LOLR facilities in place, broker-dealers delevered relatively slowly, and the weaker among them delevered most slowly. Only anecdotal evidence, however, can connect these facts with the motives driving broker-dealer behavior. To that end, this paper reviews statements of broker-dealer management during earnings calls, like the Merrill Lynch call recounted earlier. This body of evidence indicates quite clearly that management understood the significance of existing LOLR facilities, but set deleveraging strategies to maximize their firms' private interests.

The paper concludes by exploring two sets of policies motivated by the theoretical and empirical results just described. The first set of policies is to mitigate the moral hazard of reduced deleveraging directly, i.e., by conditioning access to LOLR facilities on some degree of leverage reduction or asset sales. The extent of the conditioning would be calibrated, of course, so as not to sacrifice unduly the systemic benefits of the LOLR facilities. Importantly, to this end, the conditioning can be implemented so as to exlclude funding of customer positions. The second set of policies is to encourage institutions with relatively clean balance sheets to use the LOLR facilities to purchase illiquid assets. This policy could temporarily support the price of such assets while facilitating, rather than slowing, the deleveraging of troubled financial institutions.

The outline of the paper is as follows. Section 2 reviews the related literature. Section 3 presents and analyzes the model with an exogenously-determined illiquid asset price while Section 4 extends the model to an endogenously-determined price. Section 5 presents the case study of broker-dealer deleveraging from '07 to '09. Section 6 explores policies to mitigage the moral-hazard consequences of LOLR. Section 7 concludes. 


\section{Literature Review}

Recent theoretical literature recognizes the nexus of bank liquidity, solvency, and LOLR policies. Rochet and Vives (2004) and Diamond and Rajan (2005) stress that it is generally difficult to distinguish between an illiquid and an insolvent institution, which implies that a central bank can easily find itself lending to an insolvent institution. Their results suggest that the much celebrated prescription of Bagehot (1873) for LOLR policies might be right after all. He proposed that the central bank, in times of panic, freely advance reserves to any private bank able to offer "what in ordinary times is reckoned a good security" as collateral, but at a penalty rate, so as to discourage applications from banks not really in need of funds. While Bagehot was concerned primarily with the practical goal of conserving limited reserves, this literature provides a new rationale for such intervention. ${ }^{3}$

On the theoretical front, this paper is related both to Rochet and Vives (2004) and Diamond and Rajan (2005), but is more specifically focused on understanding how LOLR facilities affect the deleveraging decisions of financial institutions and the market prices of illiquid assets. More specifically, when does the moral hazard effect of LOLR facilities, which reduces deleveraging at eligible firms, increase their likelihood of default, despite the fact that LOLR increases asset prices?

On the empirical front, evidence has accumulated on how the provision of central bank liquidity relaxes institutions' funding constraints, and thereby supports the prices of illiquid assets. See Fleming (2012), for example, for a review of studies documenting that the Federal Reserve's suite of LOLR policies during the recent financial crisis lowered inter-bank borrowing spreads and raised the prices of asset-backed and mortgage-backed securities. Empirical work on the ex-ante incentives of firms participating in LOLR facilities, however, like the case study in this paper, is a relatively new line of investigation.

Acharya et al. (2011) find that the weaker broker-dealers borrowed at the Federal Reserve's TSLF and PDCF, even after controlling for the size of their illiquid inventory. Acharya and Steffen (2012) document that under-capitalized banks in the peripheral countries, especially Spain and

\footnotetext{
${ }^{3}$ See Fischer (1999) for an excellent survey of LOLR policy prescriptions and the literature that evolved from these prescriptions. Although Fischer's focus is on the role that can be played by the International Monetary Fund (IMF) as the international LOLR when sovereign or banking crises need to be contained from spreading across borders, he also succinctly presents the argument underlying the moral hazard induced by LOLR, including domestic LOLR. He recognizes that, while moral hazard needs to be contained, it is unlikely to be eliminated entirely through the design of LOLR facilities.
} 
Italy, used the ECB's LTRO to increase their exposures to relatively risky domestic bonds, thus tightening the feedback loop between banks and sovereigns in the periphery. ${ }^{4}$ Drechsler et al. (2013), using data on collateral tendered to the ECB, find that that liquidity facility was used by some of the riskier firms in the periphery to hold on to their illiquid and risky positions, which included not only sovereign credit but also mortgage-related investments.

Implicit in much of this empirical work is the underlying fact that the terms (e.g., tenor, interest rate, haircut, and collateral eligibility) of the LOLR operations of the Federal Reserve, the ECB, and the Bank of England did not, for the most part, depend on the health of eligible banks and broker-dealers. ${ }^{5}$ One rationale for this kind of extensive and unconditional support from central banks is that banking sector recapitalizations, which can easily require public funds, may not be feasible due to political economy constraints, such as myopia, as in Acharya and Rajan (2013). Growing empirical evidence, including that in this paper, however, clarifies that central bank support is no panacea as it has the unintended consequence of slowing down the deleveraging process and potentially increasing the likelihood of future crises. Indeed, unconditional central bank support can weaken the political resolve to ensure timely recapitalization of distressed parts of the financial sector.

One policy we explore in this paper that might address this unintended consequence is to condition LOLR support on participant solvency. This policy is related to Acharya and Backus (2009) who argued that central bank liquidity provision should be made conditional on adequate solvency estimates of financial institutions, e.g., maximum leverage ratio or minimum capital adequacy. Lack of such conditionality can allow weaknesses of these institutions to fester, creating "zombie banks" and further deepening the crisis. ${ }^{6}$ A related policy we explore in this paper is to condition LOLR support on a certain amount of deleveraging or asset sales, which would likely stabilize the borrower.

Both of these policies are related to the discussion in the international context, along the

\footnotetext{
${ }^{4}$ See Acharya, Drechsler and Schnabl (2010, 2012) for theoretical and empirical illustrations of how financial-sector and sovereign credit risks impact one another.

${ }^{5}$ In a particularly startling example, Acharya and Steffen (2012) show that the Bank of Cyprus, using ECB financing, appears to have quadrupled its holdings of Greek debt 2010-11.

${ }^{6}$ Caballero, Hoshi and Kashyap (2008), in the context of the Japanese banking crisis of the 1990s, attributes the phenomenon of "zombie banks" lending to "zombie firms," along with the resulting credit crunch, to the excessive forbearance of the Bank of Japan. Diamond and Rajan (2011) argue that delaying fire sales in expectation of central bank or government support can increase the returns to liquidity (i.e., to the capacity for acquiring assets that are eventually sold in fire sales) and lead to an ex-ante freeze in credit markets.
} 
lines of Fischer (1999). Emergency support by the International Monetary Fund (IMF), a form of international LOLR, can allow participating countries to slow structural reforms, which might make future sovereign crises more likely. This moral hazard justifies both linking lending rates to measures of solvency and conditioning IMF support on strict and possibly unpopular structural reforms. Fischer (1999) recognizes that an extreme form of conditioning, e.g., not lending to certain countries altogether, may lack credibility if they or their banks are too big to fail. In that case Fischer (1999) recommends that those receiving support be pushed by the IMF toward growthfriendly reforms with respect to, for example, fiscal prudence, monetary and financial transparency, securities markets standards, bankruptcy regulations, and entry of foreign banks.

Another policy we explore in this paper is to provide liquidity not to distressed financial intermediaries, but to potential buyers of distressed assets. These potential buyers must be financially strong, of course, so as not merely to shift the insolvency problem from one set of firms to another. He, Khang and Krishnamurthy (2010), studying the adjustment of balance-sheet assets in the United States from 2007-2009, find that much of the leverage shifted from segments of the financial sector without access to LOLR financing (i.e., hedge funds and initially broker-dealers) towards segments covered by LOLR financing (i.e., commercial banks) or by government support (i.e., Fannie Mae and Freddie Mac). The policy explored in this paper is more nuanced than such an arrangement, calling for the provision of LOLR financing to any healthy, buyers of assets rather than to a pre-ordained set of financial firms, such as commercial banks and thrifts, that already happen to have access to LOLR facilities. Indeed, some firms with such access or with government support (e.g., Washington Mutual, Citibank, GSEs) were excessively leveraged at the time they received public or central bank support. Judicious design of LOLR policy can prevent the shift of leverage between firms in a way that has adverse or uncertain consequences for financial stability. Indeed, providing liquidity to healthy potential buyers of assets can improve the ex-ante incentives of financial firms to manage risks prudently and to keep capacity to purchase assets opportunistically. ${ }^{7}$

\footnotetext{
${ }^{7}$ A result from Acharya and Yorulmazer (2008) resonates here. In that model, in the case of multiple bank failures, the optimal use of fiscal funds is to transfer liquidity to survivors. This curbs the ex-ante incentives for banks to herd in owning correlated assets so as to induce bailouts in cases of en masse failures.
} 


\section{The Model with an Exogenous Illiquid Asset Price}

This section presents a model designed to explore how LOLR facilities might affect the deleveraging policy of a bank and its probability of default. The setting is the collision of a financial crisis and an intermediary engaged in maturity and liquidity transformation. More specifically, a bank owns a long-term, illiquid asset that has been funded, in part, by short-term debt. A poor economy has reduced the expected cash flows of the asset, and distressed market conditions have depressed the asset's price even further. Under these circumstances, the bank would like to hold on to its undervalued, illiquid asset, but, should its cash flows turn out to be particularly low, and should the bank not be able to roll over enough of its short-term debt, the ensuing bankruptcy would wipe out all of the bank's equity. The bank will, therefore, choose to sell some of its illiquid asset holdings. How much it chooses to sell, i.e., the extent to which it chooses to delever, depends crucially on the extent to which it can fund its illiquid asset holdings as its short-term debt comes due. And the availability of such funding during a financial crisis often depends on the the existence of an LOLR facility.

The model yields two main results. First, an LOLR facility reduces a bank's optimal amount of deleveraging. Very simply, the ability to draw on LOLR funding when needed makes it less risky for a bank to hold on to its illiquid assets. Second, LOLR facilities increase a bank's probability of default. It is clearly true that, for a given portfolio, the availability of LOLR funding lowers the bank's probability of default. But the LOLR facility increases the bank's holdings of the illiquid asset, as per the first result, which increases the bank's probability of default. Despite the two offsetting effects on the probability of default, in the model of this section the moral hazard effect of increased risk taking always outweighs the liquidity insurance effect of available funding so as to increase the bank's probability of default.

Numerical examples of the model illustrate these two main results, along with the relationship between initial leverage and the optimal amount of deleveraging. It turns out that, for large enough initial leverage, a bank chooses optimally not to delever at all. As it becomes difficult to avoid bankruptcy, even with the LOLR facility, it is best for equity to hold on to the upside potential of the illiquid asset as long as possible. 


\subsection{Assumptions and Notation}

The model has three dates, which are labeled 0,1 , and 2, and two assets. The liquid asset has a price that equals 1 on every date, which implies a riskless rate equal to 0 . The illiquid asset pays $x_{1}=\bar{x}_{1}+u$ on date 1 and $x_{2}>0$ on date 2 , where $\bar{x}_{1}$ and $x_{2}$ are constants and $u$ is stochastic with cumulative distribution and density functions of $G(\cdot)$ and $g(\cdot)$, respectively. The stochastic, date- 1 cash flow of the illiquid asset introduces a risk of bankruptcy to banks that are funding the asset with short-term debt, i.e., with debt that matures on date 1 . The positive, date- 2 cash flow of the asset motivates banks to avoid bankruptcy on date 1.

The price of the illiquid asset is given exogenously as $p$ per unit, where $p<\bar{x}_{1}+E[u]+x_{2}$ and $E(\cdot)$ is the expectations operator. This condition on price ensures that the illiquid asset is desirable as a positive expected value investment. The assumption of price exogeneity, by the way, as mentioned in the introduction, will be relaxed in the next section.

Funding or repurchase markets work in the model as follows. A holder of illiquid assets can borrow on date 1 , on a secured basis, a fraction $l<1$ of the date- 2 cash flow of those assets. The amount borrowed must be repaid on date 2. Borrowing and lending are effected through the liquid asset at an interest rate of zero, as discussed earlier. Without access to an LOLR facility, the fraction $l$ represents the fraction advanced to a holder of the illiquid asset by private funding markets. With access to an LOLR facility, the fraction $l$ represents the maximum of the fraction advanced by private funding markets and the fraction advanced by the LOLR facility. This interpretation highlights the following phenomenon. When an LOLR facility stands ready to advance a fraction $l$ to a particular set of counterparties, private funding markets are often willing to advance that same fraction $l$ to that same set of counterparties. After all, should a lender need its funds returned, the borrowing counterparty can always turn to the central bank for funds. Put another way, when $l$ is offered by the LOLR facility and is the highest advance fraction available in the market, holders of the illiquid asset might nevertheless be borrowing that advance from private markets.

The bank in the model is endowed on date 0 with $e^{L}$ of the liquid asset, $e^{I}$ of the illiquid asset, and short-term debt outstanding of $B$, which must be repaid on date 1 . To discharge this date-1 debt obligation, the bank may borrow at the LOLR advance rate of $l$, as just described. 
The bank is assumed to be solvent in the sense that the market value of its assets exceeds its debt obligations, i.e., $e^{L}+p e^{I}>B$.

Given its endowment, the nature of the assets, and its access to LOLR funding, the bank, on date 0 , maximizes the value of its equity by selling some quantity $\alpha$ of the illiquid asset for $p$ per unit (and investing the proceeds in the liquid asset). Note that, since bank equity is worthless if the bank defaults on date 1 , the date- 0 value of the equity equals the expected value of its net worth on date- 2 conditional on the bank's ability to discharge its date-1 debt.

Table 1 summarizes the bank's cash flows for a given $\alpha$ assuming no date- 1 default. The bank starts on date 0 with liquid and illiquid asset endowments of $e^{L}$ and $e^{I}$, respectively. On date 0 the bank chooses to sell $\alpha$ of the illiquid asset for $p \alpha$ of the liquid asset. On date 1 , the bank carries over its liquid asset balance from date 0; collects its date-1 illiquid asset cash flow of $\left(e^{I}-\alpha\right) x_{1}$, which it invests in the liquid asset; borrows $\left(e^{I}-\alpha\right) l x_{2}$ from the LOLR facility in the form of the liquid asset; and pays off its debt of $B$ from its liquid asset holdings. Finally, on date 2 , the bank carries over its date- 1 liquid asset balance; collects its date-2 illiquid asset cash flow of $\left(e^{I}-\alpha\right) x_{2}$, which it converts to liquid assets; and pays off its date-1 LOLR borrowing from its liquid asset holdings. The value of the bank's equity, therefore, conditional on no default, is simply its expected date-2 liquid asset balance.

Note the implicit assumption of this discussion and of Table 1 is that the bank always borrows the most it can borrow from the LOLR facility on date 1 . This is a harmless simplification in the context of this model. First, there are some realizations of $u$ for which the bank does need to borrow this maximum amount to avoid bankruptcy. Second, with an effective interest rate of 0 , there is no cost to borrowing more than necessary from the facility on date 1 and repaying the full amount on date 2 .

For a final observation on the model setting, make the sensible assumption that date-1 LOLR loans are available to the bank only if it does not default on date 1 . In that case, the bank never defaults on its LOLR borrowing: it is advanced only a fraction $l<1$ of its deterministic date-2 cash flow. More specifically, the bank is advanced $\left(e^{I}-\alpha\right) l x_{2}$ on date 1 , while, ruling out a date-1 default, it collects the greater quantity, $\left(e^{I}-\alpha\right) x_{2}$, with certainty. 


\subsection{The Bank's Optimal Deleveraging Policy}

The bank's problem is to choose $\alpha$ on date 0 so as to maximize its expected date- 2 net worth conditional on not defaulting on date 1. Focusing for a moment on the condition for not defaulting, the bank can meet its debt obligation so long as $e^{L}+p \alpha+\left(e^{I}-\alpha\right) x_{1}+\left(e^{I}-\alpha\right) l x_{2} \geq B$, where $x_{1}=\bar{x}_{1}+u$. Furthermore, since the only stochastic component of this condition is $u$, there is some realization of $u$ below which the bank defaults and above which the bank does not default. Denoting this default threshold value of $u$ as $u_{B}$, the condition for no default can be written as

$$
u \geq u_{B} \equiv \frac{1}{\left(e^{I}-\alpha\right)}\left[B-e^{L}-\left(e^{I}-\alpha\right) \bar{x}_{1}-\left(e^{I}-\alpha\right) l x_{2}-p \alpha\right]
$$

The equity value of the bank, $E$, that is, its date- 2 net worth conditional on not defaulting, can now be written as

$$
E=\int_{u_{B}}^{\infty}\left[e^{L}+p \alpha-B+\left(e^{I}-\alpha\right) x_{1}+\left(e^{I}-\alpha\right) x_{2}\right] g(u) d u
$$

where the integrand is the date-2 liquid asset holding of the bank conditional on no default, as given in Table 1. Rewriting this integrand in terms of $u_{B}$,

$$
E=\left(e^{I}-\alpha\right) \int_{u_{B}}^{\infty}\left[\left(u-u_{B}\right)+(1-l) x_{2}\right] g(u) d u
$$

Maximizing $E$ with respect to $\alpha$ gives this first-order condition:

$$
\frac{\partial E}{\partial \alpha}=\frac{-E}{\left(e^{I}-\alpha\right)}-\left(e^{I}-\alpha\right)\left[1-G\left(u_{B}\right)+(1-l) x_{2} g\left(u_{B}\right)\right]\left(\frac{-\partial u_{B}}{\partial \alpha}\right)=0
$$

The partial derivative of $u_{B}$ with respect to $\alpha$ can be calculated directly from the definition of $u_{B}$ in equation (1),

$$
\frac{\partial u_{B}}{\partial \alpha}=\frac{-e^{L}-e^{I} p+B}{\left(e^{I}-\alpha\right)^{2}}<0
$$

where the inequality follows from the bank's solvency condition given in the previous subsection. 
Intuitively, as the bank sells more of the illiquid asset, the default threshold falls, i.e., bigger adverse shocks are required to trigger a default, which means that the probability of default falls. In any case, substituting expression (5) into (4) gives the final form of the first order condition: ${ }^{8}$

$$
\frac{\partial E}{\partial \alpha}=\frac{1}{\left(e^{I}-\alpha\right)}\left[-E+\left(e^{L}+e^{I} p-B\right)\left(1-G\left(u_{B}\right)+(1-l) x_{2} g\left(u_{B}\right)\right)\right]=0
$$

\subsection{The Effect of LOLR on Deleveraging and Default Probabilities}

This subsection presents two results of the model, namely, that an LOLR facility reduces the extent to which a bank delevers and increases its probability of default. The proofs are in Appendix A.

PROPOSITION 1: $\frac{d \alpha^{*}}{d l} \leq 0$.

The intuition of Proposition 1 is straightforward. The more a bank can borrow against a given illiquid asset holding, the lower its probability of default. Alternatively, increasing $l$ makes illiquid asset holdings more affordable in terms of default risk. Therefore, a bank responds to more generous funding terms by optimally choosing to delever less. Recalling the discussion of $l$ from earler in this section, by the way, an increase in $l$ can be interpreted either as an LOLR facility providing better funding terms than previously available private funding or, more literally, as an LOLR facility liberalizing its previously existing lending terms.

PROPOSITION 2: Unless $\alpha^{*}=0, \frac{d u_{B}}{d l}>0$

To develop some intution for Proposition 2, express $\frac{d u_{B}}{d l}$ as the sum of two terms:

$$
\frac{d u_{B}}{d l}=\frac{\partial u_{B}}{\partial l}+\frac{\partial u_{B}}{\partial \alpha} \frac{d \alpha^{*}}{d l}
$$

\footnotetext{
${ }^{8}$ This first order condition does not always obtain, that is, under certain conditions the bank will be at a corner solution. Furthermore, the transition to a corner solution may not be continuous in $l$ or $B$. Such corner solutions are interesting because a jump from a positive, optimal $\alpha$ to 0 represents a shift in strategy from deleveraging to pure risk-shifting.
} 
The first term on the right hand side is the liquidity insurance effect. The more a bank can borrow against the illiquid asset, the lower its default threshold and the lower its probability of

default. It is clear from equation (1), in fact, that $\frac{\partial u_{B}}{\partial l}=-x_{2}<0$, i.e., the liquidity insurance effect always decreases bank risk.

The second term on the right hand side of equation (7) is the moral hazard effect. The bank takes account of a change in $l$ in its optimal deleveraging strategy. Knowing that $l$ has increased, the bank chooses to hold more of the illiquid asset, or, equivalently, chooses a lower $\alpha$, as shown in Proposition 1. But this reduced deleveraging increases the default threshold and increases the probability of default, as shown in (5). Mathematically, since both factors of this second term are negative, their product is positive. Hence, the moral hazard effect always adds to bank risk.

With the liquidity insurance effect decreasing risk and the moral hazard effect increasing risk, the real thrust of Proposition 2 is the conclusion that the moral hazard effect dominates so that LOLR facilities increase bank risk. This result will not be as strong in the next section, where the illiquid asset price is determined endogenously. For now, however, the paper turns to numerical examples of the model currently under consideration.

\subsection{Numerical Examples and Comparative Statics}

In the spirit of the model just presented, the setting of these examples is a bank that, in better times, borrowed short-term funds to finance the purchase of a long-term, relatively illiquid asset. The quality of the asset then deteriorated, i.e., its price fell, its expected cash flows fell, the volatility of its cash flows increased, and the haircut required to fund the asset in private markets increased. As a result, the bank may very well not be able to raise sufficient funds when it needs to refinance the asset to pay off outstanding short-term debt. In other words, the bank may very well default on its short-term debt and, consequently, lose the longer-term cash flows of the asset. The bank chooses, therefore, to sell some portion of its illiquid asset holdings. Crucial to this decision, of course, are the terms of any LOLR lending facility through which the bank can raise funds on the collateral of its remaining asset holdings.

\subsubsection{Base Case Parameters}

Consider the following base case: 
i. A bank is endowed with one unit of the illiquid asset at time 0 . This asset pays $1+u$ at time 1 and 1.10 at time 2 , where $u$ is normally distributed with a mean $\mu=0$ and a standard deviation $\sigma=0.25$.

ii. The bank has short-term debt outstanding, which requires a payment of 1.75 on date 1 .

iii. Through an LOLR secured-lending facility, the bank may, on date 1 , borrow $85 \%$ of the date- 2 cash flow of the risky asset. This borrowing must be repaid on date 2 .

iv. The price of the risky asset is 2.098. This price is exogenous in this setting, but will emerge as the general equilibrium price in an example later in the paper.

This bank is at significant risk of default. Say that the asset were to experience a one standard-deviation adverse shock, i.e., $u=-0.25$, so that its date- 1 cash flow were 0.75 . Then, even after raising 0.935 through the LOLR (i.e., $85 \%$ of the date-2 cash flow of 1.10), the bank's cash balance is only $0.75+0.935$, or 1.685 , which is insufficient to repay the maturing debt of 1.75 . One measure of the riskiness of this bank's balance sheet is its illiquid inventory leverage. Its only asset is one unit of the risky asset, which is worth 2.098. The book value of its debt is 1.75 , which gives a book equity of $2.098-1.75$, or .348. Hence, the bank's illiquid inventory leverage is $\frac{2.098}{0.348}$, or a bit over 6.0 .

\subsubsection{Results}

Recognizing that holding the full unit endowment of the illiquid asset is too risky, the bank chooses to sell $\alpha$ of that asset so as to maximize its equity value. Using the base case parameters, the optimal $\alpha$ turns out to be 0.60 , or, equivalently, the bank chooses to retain only 0.40 of its original unit position. Furthermore, a holding of this reduced size implies a probability of default on date 1 of $0.2 \%$.

Figures 1 (a) and 1 (b) show how the bank's optimal $\alpha$, and probability of default change with $l$, the fraction of the date- 2 cash flow that can be financed through the LOLR facility. Figure 1 (a) shows that $\alpha$ decreases with $l$. The more generous the LOLR, the more the bank can raise on the date-2 cash flow of the illiquid asset, and the less the bank chooses to delever. This is the moral hazard effect of LOLR facilities. Imagine for a moment that the private market would finance only 
$50 \%$ of the date- 2 cash flow. Then, according to Figure 1 (a), the bank would sell about 0.76 of its illiquid asset holdings. Given the existence of an LOLR facility with $l=85 \%$, however, the bank optimally sells only 0.60 of its holdings. Note too that as the $l$ rises above $88 \%, \alpha$ drops to 0 , i.e., the bank chooses not to delever at all.

Figure 1 (b) shows that the bank's probability of default increases with $l$. At $l=50 \%$ the probability of default is about $0.02 \%$, while at $l=85 \%$ the probability of default is more than 10 times higher at about $0.22 \%$. For any fixed $\alpha$, the probability of default decreases with $l$ : the more the LOLR facility lends against the illiquid asset, the less likely a default. However, because the bank reduces $\alpha$ as the LOLR facility becomes more generous, the net effect is to increase its probability of default. In this way, one of the goals of LOLR, namely, to reduce the likelihood of bank defaults, is fully subverted by the moral hazard effect of reduced deleveraging. Note that moving to the highest levels of $l$ in Figure 1 (b), like 89\%, at which level the bank chooses not to delever at all, the probability of default rises dramatically to about $18 \%$, which is off the scale of Figure 1 (b). Any further increase in $l$ will, of course, lower the probability of default since $\alpha$ is from then on fixed at 0 .

Figures 2 (a), 2 (b), and 2 (c) show how the bank's optimal $\alpha$ and probability of default change with illiquid inventory leverage, a measure of the risk of a bank's balance sheet. Leverage is varied for these figures by varying $B$, the amount of debt due on date 1 . For very low leverage, when the probability of default is zero, the bank does not need to sell any of its illiquid asset. For intermediate levels of leverage, the bank chooses $\alpha$, the extent of deleveraging, to target a probability of default of approximately $0.22 \%$. Finally, for even higher levels of leverage, the bank chooses not to delever at all and the probability of default jumps to nearly $50 \%$ and higher, which, as that is off the scale of Figure 2 (b), is shown in Figure 2 (c). At these elevated risk levels, the relatively small increase in survival probability from deleveraging does not compensate for the foregone returns on the illiquid asset. This result will be invoked later in the paper to explain, at least in part, why particular investment banks failed to reduce illiquid inventory leverage in 2008. 


\section{The Model with an Endogenous Illiquid Asset Price}

No discussion of bank deleveraging can be complete without some discussion of the behavior of those who purchase the illiquid asset that the banks are selling. The most likely purchasers certainly need to have the balance sheet and risk capacity to purchase distressed assets in a time of crisis, but they must also be knowledgeable about the asset and operationally and legally prepared to own it. These likely purchasers could include banks with less-levered balance sheets, other levered money with spare capital and risk capacity, e.g., hedge funds, and real money, e.g., wealth management institutions, pension funds, and insurance companies.

With respect to the results of this paper, the interaction of the buyers of the asset and the banks will determine how the price of the illiquid asset changes as the terms of an LOLR facility become more or less generous. How robust are the results of the model of Section 3, in which price is fixed and exogenous, to a setting in which price is endogenously determined?

This section lays out a model in which the price of the illiquid asset is determined by the supply from banks and the demand from potential buyers. While it is difficult to draw general conclusions from this substantially more complicated world, it is not difficult to show numerical examples in which the results of the previous section obtain, i.e., in which LOLR facilities reduce bank deleveraging and increase the probability of bank default.

The model of this section allows for the possibility that the buyers have access to an LOLR facility, either along with the banks or instead of the banks. Numerical results in these cases will be invoked in the policy discussion of Section 6 .

\subsection{Assumptions and Notation}

The properties of the asset, the rules of the LOLR facility, and the characteristics of the bank are the same here as in Section 3. Therefore, changing notation by indexing quantities, the bank's optimization problem here is identical to that of Section 3, i.e.,

$$
\max _{\alpha^{B a n k}} E_{\text {Bank }}=\left(e^{I, \text { Bank }}-\alpha^{\text {Bank }}\right) \int_{u_{B}^{B a n k}}^{\infty}\left[\left(u-u_{B}^{\text {Bank }}\right)+\left(1-l^{\text {Bank }}\right) x_{2}\right] g(u) d u
$$

The model notation for the buyer is very much like that for the bank. The buyer has 
endowments of the liquid and illiquid assets, it has debt due on date 1, and it has access to the LOLR facility with the parameter $l^{\text {Buyer }}$. The buyer's decision variable, however, which is denoted $\alpha^{\text {Buyer }}$, gives the amount of the illiquid asset bought, rather than sold, on date 0 . Table 2 puts all of this together to illustrate the cash flows of the buyer for a given $\alpha^{\text {Buyer }}$ conditional on no default. This table is, of course, the buyer's analog of Table 1.

The use of two different LOLR parameters, $l^{\text {Bank }}$ and $l^{\text {Buyer }}$, requires some clarification. This notation is simply a formalism for several special cases of interest. If the bank has access to an LOLR facility but the buyer does not, $l^{\text {Bank }}$ denotes the parameter of the LOLR facility while $l^{\text {Buyer }}$ denotes the best available advance in private funding markets. If the buyer has access to the facility while the bank does not, a case considered in the numerical results to follow, $l^{\text {Bank }}$ denotes a private funding market advance while $l^{\text {Buyer }}$ denotes the facility's advance. To take one additional example, if both the bank and the buyer have access to the same LOLR facility on the same terms, then $l^{\text {Bank }}=l^{\text {Buyer }}$.

With notation now specified, the buyer's optimization problem can be derived along the same lines as that of the bank, and turns out to be

$$
\max _{\alpha^{B u y e r}} E_{\text {Buyer }}=\left(e^{I, \text { Buyer }}+\alpha^{\text {Buyer }}\right) \int_{u_{B}^{\text {Buyer }}}^{\infty}\left[\left(u-u_{B}^{\text {Buyer }}\right)+\left(1-l^{\text {Buyer }}\right) x_{2}\right] g(u) d u
$$

The feasible range for $\alpha^{\text {Bank }}$ and $\alpha^{\text {Buyer }}$ has not been explicitly included in the recording of these two optimization problems, but the restrictions are straightforward. The bank can only sell the illiquid assets with which it was endowed; the buyer can never buy more of the illiquid asset than the bank's endowment; the buyer cannot spend more on its purchases of illiquid assets than it has in liquid assets; etc.

The bank and the buyer optimally choose an amount of the illiquid asset to sell and to buy, respectively. The market clears when the amount the bank chooses to sell equals the amount the buyer chooses to buy. The resulting equilibrium is described more formally as follows:

DEFINITION 1: A competitive equilibrium is an allocation $\left\{\alpha^{\text {Bank* }}, \alpha^{\text {Buyer* }}\right\}$ and a price $p^{*}$ such that, given $p^{*}, \alpha^{\text {Bank* }}$ solves equation (8), $\alpha^{\text {Buyer* }}$ solves equation (9), and the market clears in that 


$$
\alpha^{\text {Bank* }}=\alpha^{\text {Buyer* }}
$$

This version of the model, with the endogenous price determination of the illiquid asset, can generate a wide variety of results depending on the endowments and leverage of the banks and buyers. ${ }^{9}$ For the purposes of this paper, one conceptually appealing restriction when the bank alone has access to the LOLR facility is to consider only equilibria in which LOLR facilities increase the price of the illiquid asset. Intuitively, making it easier for the market to fund the illiquid asset should increase rather than decrease its traded price. To express this restriction mathematically, implicitly differentiate equation (10) to obtain

$$
\frac{\partial \alpha^{\text {Bank }}}{\partial l^{\text {Bank }}}+\frac{\partial \alpha^{\text {Bank }}}{\partial p} \frac{d p}{d l^{\text {Bank }}}-\frac{\partial \alpha^{\text {Buyer }}}{\partial p} \frac{d p}{d l^{\text {Bank }}}=0
$$

or

$$
\frac{d p}{d l^{\text {Bank }}}=\frac{-\frac{\partial \alpha^{\text {Bank }}}{\partial l^{\text {Bank }}}}{\frac{\partial \alpha^{\text {Bank }}}{\partial p}-\frac{\partial \alpha^{\text {Buyer }}}{\partial p}}
$$

From Proposition $1, \frac{\partial \alpha^{\text {Bank }}}{\partial l^{\text {Bank }}} \geq 0$, with strict equality so long as $\alpha^{*}>0$. Therefore, $\frac{d p}{d l^{\text {Bank }}}>0$ if and only if

$$
\frac{\partial \alpha^{\text {Bank }}}{\partial p}-\frac{\partial \alpha^{\text {Buyer }}}{\partial p}>0
$$

This condition reveals that the restriction of equilibria to cases in which the price increases with $l^{\text {Bank }}$ is met when the bank supply curve and the buyer demand curve are restricted to their expected slopes. If the bank optimally chooses to sell more of the illiquid asset as its price increases, then the first term of equation (13) is positive. If the buyer optimally buys less of the illiquid asset as its price increases, then the contribution of the second term of equation (13) is positive as well.

\footnotetext{
${ }^{9}$ In certain parameterizations, for example, in which the bank is very highly levered, a U-shaped bank supply curve and a downward-sloping buyer demand curve give rise to multiple equilibria.
} 
Hence, if both curves slope as expected, the inequality of equation (13) does hold and, as just shown, price increases with $l$.

\subsection{The Effect of LOLR on Default Probabilities}

In the version of the model with an exogenously determined illiquid asset price, equation (7) revealed that a liquidity insurance effect and a moral hazard effect explain the effect of an LOLR facility on a bank's default threshold and its probabilty of default. With an endogenously determined price, the total change in $u_{B}$ for a change in $l$ has an extra term. (Note that superscripts explicitly denoting bank quantities are omitted here.)

$$
\frac{d u_{B}}{d l}=\frac{\partial u_{B}}{\partial l}+\frac{\partial u_{B}}{\partial \alpha} \frac{d \alpha^{*}}{d l}+\frac{\partial u_{B}}{\partial p} \frac{d p^{*}}{d l}
$$

The first and second terms of equation (14) are the liquidity insurance and moral hazard effects, respectively, just as in equation (7). The third term can be called the price externality effect. As $l$ increases for a given price, each perfectly competitive bank reduces its sales of the illiquid asset. But, with a downward-sloping buyer demand curve, the aggregate reduction in sales by the banking sector increases the equilibrium price. This price increase, in turn, raises the value of the representative bank's assets and lowers it default threshold and probability of default. More

mathematically, with the restriction of equilibria to those in which $\frac{d p^{*}}{d l}>0$ and with $\frac{\partial u_{B}}{\partial p}<0$, the price externality effect in equation (14) is negative, i.e., it lowers the bank's default threshold and its probability of default.

To summarize, Proposition 2 argued that, with an exogenously determined illiquid asset price, the moral hazard effect dominates the liquidity insurance effect so that an LOLR facility increases the probability of a bank's default. This section shows that, with price determined endogenously, the price externality effect decreases the probability of default. Therefore, with an endogenously determined price, a bank's probability of default may increase or decrease depending on the relative sizes of the various effects. In the numerical results of the following subsection, for example, at relatively low values of $l$ the LOLR facility decreases bank risk while, at relatively high values of $l$, the LOLR facility increases bank risk. 


\subsection{Numerical Examples and Comparative Statics}

The numerical examples of Section 3.4 showed that more generous LOLR facilities result in less bank deleveraging and higher probabilities of default. These results, however, did not consider the possibility that changes in the terms of LOLR facilities change the price of the illiquid asset and, through that price effect, change deleveraging decisions and probabilities of default. In the examples of this section, more generous LOLR facilities do affect price, but still result in less bank deleveraging and can still result in higher probabilities of default.

In the spirit of the model of Section 4, the examples here include an investor, or "buyer," who is familiar with and who owns the illiquid asset, but who is significantly less leveraged. This lower balance sheet risk makes it worthwhile for the buyer to purchase the illiquid asset at distressed prices from the highly-levered banks.

To highlight the fact that LOLR facilities are typically open only to banks, Sections 4.3 .1 and 4.3.2 continue to assume that the bank can borrow some fraction $l$ of the date- 2 cash flow of the risky asset, as in the examples of Section 3.4, but assume that the buyer has no access to such borrowing. It would not change the qualitative numerical results, however, were the buyer able to borrow some smaller fraction of the date- 2 cash flow of the illiquid asset in private funding markets.

Finally, to explore an important policy implication of the framework of this paper, Section 4.3.3 assumes that the buyer, instead of the seller, has access to the LOLR facility. The bank, barred from using that window, has access only to private funding markets, which do not advance as much against the illiquid asset as does the LOLR facility.

\subsubsection{Base Case Parameters}

The parameters of the bank in this example are the same as in the partial equilibrium case of Section 3.5. The parameters of the buyer may be described as follows:

i. The buyer holds 1.70 of the liquid asset, which has a fixed price of 1.0.

ii. The buyer holds one unit of the illiquid asset.

iii. The buyer has short-term debt outstanding, which requires a payment of 0.50 on date 1 .

iv. The buyer cannot borrow on date 1 to finance holdings of the risky asset. 


\subsubsection{Base Case Results}

Figure 3 shows a demand curve and two supply curves for the illiquid asset under the base case parameters. The higher supply curve is for $l=80 \%$ while the lower supply curve is for $l=85 \%$. For this lower supply curve, the figure reveals that there is an equilibrium in which the bank sells about 0.60 units of the illiquid asset to the buyer at a price of 2.098 .

Increasing $l$ from $80 \%$ to $85 \%$ shifts the supply curve down, of course: for any given price, the bank optimally sells less of the illiquid asset when it can fund that asset more easily. Given the shape of the demand curve, this increase in $l$ increases the equilibrium price from 2.096 to 2.098 and lowers the equilibrium quantity traded from 0.63 to 0.60 . In this sense, the result from the fixed-price version of the model, that higher $l$ reduces bank deleveraging, can obtain when price is endogenously determined. Put another way, in the equilibria of Figure 3, despite the equilibrium price increasing as $l$ increases from $80 \%$ to $85 \%$, the banks, in equilibrium, delever less after that increase.

Figures 4 (a) through 4 (c) show the effect of $l$ on equilibrium prices and quantities. Figures 4 (a) and 4 (b) show that the equilibrium price increases and that the equilibrium quantity traded decreases as the LOLR facility becomes more generous. A higher $l$ reduces the bank's desire to supply the asset, which given the downward-sloping buyer demand, increases equilibrium price, and reduces equilibrium quantity.

Figure 4 (c) graphs the probability of the bank's and buyer's defaulting as a function of $l$. In the exogenously-determined price examples of Section 3.4, higher $l$ causes the bank to delever less, which, in turn, raises its probability of default. As Figure 4 (c) shows, however, the effect of $l$ on the probability of default in the endogenous price setting is more complicated. As just illustrated, increasing $l$ reduces equilbrium bank $\alpha$ and increases equilibrium price. The first effect, reducing sales of the risky asset, increases the probability of default, as in the exogenous price case. The second effect, however, that of increasing price, allows banks to accumulate more cash from asset sales and thus reduces the probability of default. In Figure 4 (c), the bank's probability of default falls as $l$ increases from $50 \%$ to about $76 \%$ but rises as $l$ increases beyond that. The shape of this curve is too dependent on all of the parameters chosen to draw very broad conclusions, but the qualitative result emerges quite clearly: there are parameter regions over which improved funding 
terms through an LOLR facility increase the probability of a bank default. This improvement of funding terms can, as before, be interpreted either as an improvement relative to the terms of private market funding or relative to the terms of a previously existing LOLR facility.

The probability of default for the buyer of the illiquid asset in Figure 4 (c) decreases monotonically in $l$. With higher $l$, buyers purchase less of the illiquid asset, although at a higher price per unit. In this example, however, the buyers spend monotonically less on the illiquid asset as $l$ increases and, consequently, are less likely to default.

\subsubsection{Examples with Buyer Rather than Bank Access to LOLR}

In this section, only the buyer of the risky asset is allowed access to the LOLR facility, i.e., the buyer can, on date 1 , borrow a fraction $l$ of its date- 2 cash flow. The bank, by contrast, has access only to private funding markets, which are assumed exogenously to finance $70 \%$ of the date- 2 cash flow.

Figure 5 shows the bank supply curve of the illiquid asset, along with two buyer demand curves, one for $l=5 \%$ and the other for $l=10 \%$. Higher $l$ increases the buyer demand for the asset at each price, raising equilibrium price and quantity traded.

Figures 6 (a) through 6 (c) illustrate comparative statics in this setting. Under the parameters chosen, the buyers are so lightly levered that relatively low levels of LOLR support are sufficient to generate strong demand.

Figures 6 (a) and 6 (b) confirm the intution from the shifted demand curve in Figure 5, namely, that equilibrium price and equilibrium quantity both increase with $l$. Figure 6 (c) shows that the probability of default of both the bank and the buyer decrease with $l$. In this setting with an endogenously-determined illiquid asset price, the bank delevers more at a higher $l$, so its probability of default falls. The buyer does purchase more of the risky asset as $l$ increases, but the combination of low leverage and increasing LOLR support results in a falling probability of default for the buyer as well. Further implications of these results will be explored in the policy discussion of Section 6 . 


\section{$5 \quad$ U.S. Broker-Dealer Deleveraging in 2008}

This section presents an empirical case study of broker-dealer deleveraging in 2008, which supports the conclusions of the model presented earlier. In particular, in the presence of the LOLR facilities put in place in March 2008, broker-dealers were quite slow in reducing risk through the crisis. The measure of risk used here, which is new to this paper, is called "illiquid inventory leverage." Furthermore, in a manner consistent with the model, the firms most at risk, namely Lehman Brothers and Merrill Lynch, were slower to reduce risk than the more creditworthy firms, namely Morgan Stanley and Goldman Sachs. Finally, anecdotal evidence from press releases and investor calls around earnings announcements demonstrates that firms were taking the presence of LOLR facilities as given and optimizing their own risk and return profiles independent of any broader social objectives of those facilities.

\subsection{A Short Primer on Broker-Dealer Balance Sheets and Measures of Leverage}

Table 3 consolidates various line items to present a simplified balance sheet for Morgan Stanley at the end of its first fiscal quarter in 2008. Panel A shows the balance sheet approximately as it would appear in a $10-\mathrm{Q}$ or $10-\mathrm{K}$ filing.

On the asset side, the first line gives loans in the form of "Collateralized Agreements," i.e., loans that are collateralized or secured by financial assets. When fixed income assets secure the loans, these collateralized agreements usually take the form of reverse repos. When equities secure the loans, the agreements usually take the form of stock borrows.

The second line on the asset sides gives "Financial Instruments Owned," which can be thought of as the firm's inventory. The third line, "Goodwill and Intangibles," is typically a relatively small part of the balance sheet. The fourth and last line gives "Other Assets," which includes items like receivables, customer cash and securities segregated for safekeeping, and securities received as collateral to ensure performance on various financial contracts.

On the liabilities and equity side, the "Collateralized Agreements" in the first line refer to the broker-dealer's borrowing of cash secured by financial assets. For fixed income assets this usually takes the form of repos, while, for equities, this usually takes the form of stock loans.

The second line on the liabilities and equity side gives "Shorts," securities that the firm has 
sold and will ultimately have to repurchase. The third line gives the amount outstanding of "Junior Subordinated Notes," which are included in some measures of equity. The fourth line gives "Other Borrowings," which includes payables, customer deposits, obligations to return securities posted as collateral, short-term borrowings (e.g., commercial paper), and long-term debt. The fifth and last line gives "Total Equity."

While standard for reporting purposes, the balance sheet in Panel A aggregates business activities at such a high level that it obscures very significant differences in risk across these activities. To gain some insight into the variation of risk across activities, Panel B presents a relatively well-known conceptual disaggregation of the balance sheet into "Gross" and "Net" assets. This rough cut is meant to separate gross assets, which represent relatively safe activity on behalf of customers, from net assets, which represent relatively risky activity arising from positions taken by the broker-dealer.

The first highlighted activity in the gross asset category is the "matched book" business, which consists of relatively short-term lending of cash to customers, taking securities as collateral, and relatively short-term borrowing of cash from customers, giving securities as collateral. Matchedbook assets in Panel B are $\$ 215.681$ billion collateralized cash lending and matched-book liabilities are $\$ 215.681$ billion collateralized cash borrowing. This business is regarded as relatively safe for two reasons. First, so long as collateral requirements are set appropriately, the individual collateralized agreements are relatively safe. Second, should there be a systemic liquidity shock, the brokerdealer could rapidly shrink the matched-book simply by letting the relatively short-term assets and liabilities mature and by declining to renew them. This would result in difficulties for customers, of course, and would reduce revenues at the broker-dealer, but the broker-dealer would be protecting its own viability.

Skipping over the small line item of "Goodwill and Intangibles," the second highlighted activity in the gross asset category are $\$ 233.992$ billion of "Other Gross Assets," which consist of the same assets mentioned above in the context of "Other Assets." These are also regarded as representing relatively safe activities: receivables are often collateralized; segregated customer cash and securities are custodian-like businesses; and securities received as collateral present little risk to the broker dealer. The liability-side components of "Other Gross Assets" are part of "Other Borrowings." 
Turning to the relatively risky businesses, represented by "Net Assets," the first line shows the collateralized agreements used to cover the "Shorts" on the liability side. Put another way, the broker-dealer shorted $\$ 171.111$ of securities, representing some unknown combination of stand-alone positions and hedges. The liabilities of that activity are the obligations to purchase those securities in the future. The assets are the cash loans made in the process of borrowing the securities so as to deliver securities sold short. Compared with gross asset activity, net asset activity is relatively risky due the price risk of stand-alone positions or the basis risk of hedges.

The second and largest of the "net assets" businesses is inventory holdings, represented by "Financial Instruments Owned." The broker-dealer here owned $\$ 445.837$ of assets. As indicated on the liability side, a portion of this inventory, $\$ 72.454$ billion, ${ }^{10}$ is funded by collateralized agreements, i.e., that amount of cash was borrowed on the collateral of inventory held. The rest of the inventory is effectively funded by portions of the remaining liability categories, i.e., junior subordinated notes, other borrowings, and equity. Inventory is relatively risky, like short sales, due to the price risk of stand-alone positions and the basis risk of hedges.

Inventory can be further subdivided by asset quality. Starting in 2007, broker-dealers broke down their fair-valued assets into Level 1, Level 2, and Level 3 assets. Essentially, Level 1 assets are those for which market prices are readily available; Level 2 assets are those valued through their comparability with other assets for which market prices are available; and Level 3 assets are those for which values are derived through some discounted cash flow model. This paper refers to Level 1 assets as "liquid" assets and to Level 2 and 3 assets as "illiquid assets." 11

With this background, the discussion turns to various measures of leverage, described in Panel $\mathrm{C}$, as rough indicators of risk. "Gross Leverage" is defined as the ratio of assets to total equity. For Morgan Stanley in Q1 2008, gross leverage was 32.8. Interpreting this ratio as a measure of risk, a $1 / 32.8$ or approximately $3 \%$ fall in the value of assets would wipe out the firm's equity.

\footnotetext{
${ }^{10}$ The collateralized agreements are allocated to the various activities as follows. Shorts of $\$ 171.111$ billion require that amount of collateralized agreement assets, leaving the total collateralized agreements, $\$ 386.792$ billion, minus $\$ 171.111$ billion, or $\$ 215,681$ billion, as matched-book assets. By definition, matched-book liabilities equal matchedbook assets, so subtracting $\$ 215,681$ of collateralized agreement liabilities from total collateralized agreement liabilities of $\$ 288,135$ billion, leaves $\$ 72,454$ for funding.

${ }^{11}$ Level 1 assets are almost always more liquid than Level 2 and Level 3 assets, but grouping Level 2 and Level 3 assets together makes sense because assets migrate more fluidly between these categories than between Level 1 and Level 2. During the crisis, sales of particular assets in a particular quarter provided pricing benchmarks for other assets, which could then move from Level 3 to Level 2. Similarly, a dearth of sales and, therefore, benchmark prices in a particular quarter, would push various Level 2 assets to Level 3.
} 
Leading up to the financial crisis, investment banks argued that gross leverage overstated their risk because, as discussed above, gross assets are characterized by particularly low risk. A more appropriate measure of leverage or risk, they argued, is net leverage, defined as net assets divided by tangible equity capital. By this measure, Morgan Stanley's leverage was only 16.0, which implies that net assets have to fall by $6.25 \%$ to wipe out firm equity.

While net leverage might be a better measure of risk than gross leverage, analysts and investors during the crisis were most focused on the quality of assets within net assets. How much of theses assets are loans rather than securities? How much are securitized products with somewhat impenetrable composition? How much are real-estate related? Some remarks by market participants, which illustrate the focus on asset quality at the time, are given in Appendix B.

Given the concerns of the market at the time with low quality assets, this paper defines a new measure of leverage to compare risks across firms during the financial crisis. This measure, called "Illiquid Inventory Leverage," is defined as the ratio of Level 2 and Level 3 assets to Tangible Equity Capital. As computed in Panel C of Table 3, illiquid inventory leverage for Morgan Stanley in Q1 2008 was 9.6.

The final measure of leverage listed in Panel C is "Quasi-Market Leverage," which is used more by researchers than by market participants. The idea is to get a better measure of risk by using the stock market's perception of the value of the equity instead of its book value. By this measure, Morgan Stanley's leverage was 23.7, which fell about midway between its net and gross leverage measures.

\subsection{Deleveraging by U.S. Broker-Dealers in 2008}

Table 4 reports various balance sheet elements in 2008 for the five major U.S. broker-dealers, namely, Bear Stearns, Lehman Brothers, Merrill Lynch, Morgan Stanley, and Goldman Sachs. While the story of each investment bank is somewhat idiosyncratic, there are several common themes. In particular, while both internal and external pressures pushed the firms to reduce balance sheets, holdings of relatively less risky assets were reduced first. Only when pressures intensified dramatically did the broker-dealers reduce illiquid asset holdings. Note, by the way, that Merrill Lynch's fiscal year ended in December. The fiscal years of the other investment banks ended in November, so their quarters were December through February, March through May, etc. 
Panel A shows that Bear Stearns, over Q4 2007 and Q1 2008, as the crisis started to brew, did little to reduce assets. Its perceived vulnerability to mortgage-related products, reflected in its precipitously declining market capitalization, led to the firm's absorption into JPMorgan Chase in March 2008.

Panel B relates the story for Lehman Brothers. Over Q4 2007 and Q1 2008, the firm was still expanding its balance sheet, with total assets increasing by $19.2 \%$ and net assets by $11.1 \%$. Furthermore, in another manifestation of increased risk taking, inventory became more illiquid, with holdings of Level 1 assets falling by $22.0 \%$ but illiquid inventory increasing by $18.7 \%$.

Over Q2 2008, with the fall of Bear Stearns and the market focusing its sights on Lehman Brothers as the next likely domino, the firm reduced assets substantially, i.e., total assets by $18.7 \%$ and net assets by 17.4\%. But even in this reduction mode, the firm cut Level 1 assets by a much higher $26.2 \%$ and illiquid inventory by a much lower $15.5 \%$. This deleveraging did not satisfy the market, and, in September 2008, almost immediately after reporting even smaller balance sheet reductions over Q3 2008 (not shown), the firm was forced to file for bankruptcy.

According to Panel C, in the second half of 2007 Merrill Lynch reduced total assets by $5.2 \%$, but net assets increased by $5.3 \%$, meaning that almost all of the small amount of deleveraging came from reducing the least risky business lines, like the matched book. More importantly, Merrill Lynch continued to increase its exposure to illiquid assets. Level 1 asset holdings fell $19.1 \%$ while illiquid inventory increased by $19.7 \%$. As indicated by the $30.1 \%$ decline in market capitalization, the market did not view these changes positively.

Despite the turmoil following the fall of Bear and the market view that Merrill Lynch was a domino not far behind Lehman Brothers, Merrill Lynch did little to pare its risk over the first half of 2008. Total assets, net assets, and inventory did fall, by $5.3 \%, 11.4 \%$, and $7.3 \%$, respectively, but these declines were driven by a $38.9 \%$ reduction in Level 1 assets. Illiquid inventory, which was of most concern to the market, actually increased by $6.7 \%$ ! Another significant fall in market capitalization reflected the market's lack of confidence in these adjustments as well. The firm, as shown by its Q3 2008 balance sheet, did eventually reduce its illiquid inventory. But it was too late. Earlier in September 2008, Merrill Lynch was forced to sell itself to Bank of America.

Like the other broker-dealers, Morgan Stanley, according to Panel D increased risk to illiquid products in Q4 2007 and Q1 2008, reducing total and net assets by about 8\%, but increasing illiquid 
inventory by $18.4 \%$. In response to market conditions and the fall of Bear, however, Morgan Stanley was a lot nimbler than Lehman Brothers and Merrill Lynch in reducing risky and illiquid inventory. Over Q2 2008, Morgan Stanley reduced total assets by 5.5\%, net assets by a larger 9.1\%, and illiquid inventory by an even larger $14.8 \%$. In a market generally hard on financial firms, its market capitalization over the quarter increased by $5.3 \%$.

Over the relative lull between the fall of Bear and Lehman's bankruptcy, i.e., in Morgan Stanley's Q3 2008, the firm did continue to reduce balance sheet and did continue to rotate out of illiquid products, but at a much reduced pace. Total assets, net assets, and illiquid inventory fell by $4.2 \%, 6.0 \%$, and $6.6 \%$, respectively. In the market turmoil after the bankruptcy of Lehman and the absorption of Merrill Lynch, however, Morgan Stanley felt compelled to reduce risk dramatically. Total assets fells by $33 \%$. The reductions in the riskier and less liquid assets were also significant, but not nearly as dramatic. Net assets fell by only 11.1\%, indicating that the matched book bore the brunt of the reduction in total assets. Furthermore, the $25.1 \%$ fall in inventory was achieved with a $58.0 \%$ reduction in Level 1 assets and only a 9.8\% reduction in illiquid inventory. Over this tumultuous time for financial markets, the costs of selling any inventory, but particularly illiquid inventory, were particularly punitive. Note also that, along with balance sheet reductions at this time, Morgan Stanley raised significant amounts of equity capital.

Panel E gives the balance sheet quantities for Goldman Sachs. This story is very much like that of Morgan Stanley. There was a rotation into more illiquid assets in Q4 2007 and Q1 2008; a balance sheet reduction, with particular emphasis on illiquid inventory after the fall of Bear in Q2 2008; a relatively light reduction of risk in Q3 2008 - the lull between the Bear Stearns and Lehman Brothers events - which was lighter than Morgan Stanley's reduction over that period; and, in the wake of Lehman Brothers' bankruptcy, a dramatic shrinking of the balance sheet, with significant but smaller declines in illiquid assets, together with a simultaneous significant increase in equity.

Table 5 and Figures 7 (a) and 7 (b) tell the story of broker-dealer balance sheets over 2008 in terms of leverage rather than assets. Leverage is not a perfect measure of risk, but it is more suitable than asset size for comparing risks and does combine the impacts of increasing equity and asset sales.

The qualitative stories emerging from this table and these figures are the same as just related. Firms were increasing risk leading up to the fall of Bear Stearns. In the aftermath of that event, 
Lehman Brothers and Merrill Lynch reduced risk in some ways, but not sufficiently to allay market fears. Morgan Stanley and Goldman Sachs took somewhat of a break from risk reduction in Q3 2008, but, after the bankruptcy of Lehman Brothers' in September 2008, reduced risk dramatically.

In addition to confirming these stories, the leverage data allow for a clearer comparison of risk across firms. While Lehman Brothers looked less risky than the other firms, in the sense of having lower net leverage, its illiquid inventory leverage was actually higher than most firms. The implication is that the market, concerned about the quality of various categories of assets, saw through the reported net leverage of Lehman to its real problem, as represented by its illiquid inventory leverage.

Merrill Lynch did have much lower illiquid inventory leverage than the other firms, but was a relative newcomer to mortgage-related assets. This meant that it held a large proportion of latevintage securities, which were the worst performing of real-estate related assets. Hence, its illiquid inventory was worse than those at other firms, a fact not reflected in the tables or figures. This inventory reality, in combination with its relative inexperience with the most troublesome asset classes and its relatively high net leverage, put Merrill Lynch in a more precarious position than that of Morgan Stanley or Goldman Sachs.

Figures 8 (a) and 8 (b) confirm the relationship between changes in illiquid leverage and changes in the market's perception of firm risk, where the latter is measured as changes in CDS spreads. The two figures show exactly the same data points, but Figure 8 (a) shows the data by firm while Figure 8 (b) shows the data by quarter. Focusing on Figure 8 (b), within each quarter, rising CDS spreads are associated with increases in illiquid leverage. The exceptions to this association, when CDS spreads widen dramatically, occurred when firms lost market confidence, i.e., Lehman Brothers in Q2 2008 and Merrill Lynch in Q3 2008.

\subsection{Illiquid Inventory and the Existence of LOLR Facilities}

This paper contends that the existence of LOLR facilities allows firms to put off sales of risky assets, effectively keeping the upside of such holdings while passing the downside risk on to others. It is difficult to prove this contention empirically, because it is the existence of the LOLR facilities, rather than the direct use of these facilities, that enables firms to maintain asset positions. More precisely, when the Fed stands ready to finance certain assets, private entities will finance those 
assets as well. Lenders feel safe financing these assets because, should they decide to withdraw funding at any time, the borrower can always repay the loans by financing the assets at the Fed. That the mere existence of the facilities made it easier for investment banks to fund themselves was well understood at that time, as illustrated by statements by firm officers that are reproduced in Appendix B. One statement also recounts how the existence of LOLR facilities bifurcated private markets into the relatively easy funding of "Fed-eligible" assets and the relatively difficult funding of "not Fed-eligible" assets.

Since the direct usage of LOLR facilities does not fully capture the importance of these facilities to funding markets, evidence of opportunistic risk taking has to be somewhat anecdotal. There is, however, an abundance of such anecdotal evidence. More specifically, broker-dealers state throughout 2008 that they are in profit-seeking and risk-taking mode, despite the fact that LOLR facilities have been made available - at taxpayer risk - for their survival.

A useful analogy is that of a prime broker that is financing a hedge fund that experiences financial difficulties. The prime broker does not want to cut off financing suddenly because the resulting fire sales would create unacceptable losses. Instead, the prime broker continues financing, but imposes stipulations that the hedge fund has to reduce risk or, at the very least, that future trades have to be risk reducing. This strategy allows the hedge fund to continue operations and to recover economic value should market prices move in its favor. The stipulations, however, prevent the hedge fund from playing the "heads I win, tails you lose" game with the prime broker.

Applying this analogy to LOLR facilities, it would not be unreasonable to require brokerdealers to reduce risk or at least to constrain them from increasing risk so long as the facilities are directly or indirectly supporting their funding. The anecdotal evidence, however, is that brokerdealers in 2008 acted like the agents in the model of the previous section: they took the existence of the Fed's liquidity facilities as given and optimized risk and return from their individual, narrow perspectives. Examples include a reluctance to reduce risk by selling assets at a loss, declarations of the absence of regulatory pressure to reduce risk, use of the word "optionality" and reference to market dislocations to describe risk-taking opportunities in the crisis, and parlaying access to Fed liquidity into high spreads in funding prime brokerage customers (until conditions deteriorated further and customers were cut off). In other words, at least to some extent, they did play the "heads I win, tails you lose" game. Several examples of relevant statements by officers of the 
investment banks can be found in Appendix B, but one is reproduced here as well:

As a result of the broader market dislocation, the competitive landscape has changed. Across many of our businesses, trading margins are robust and the premium on risk capital is higher than we've seen in years. In this type of environment return on assets is improving.

- David Viniar, CFO, Goldman Sachs, Q4 Earnings Call, December 16, 2008

Taking advantage of the opportunities presented by market dislocations, the failure of competitors, and high risk premiums, without consideration of the support provided by LOLR facilities, is particularly jarring.

\subsection{Broker-Dealer Usage of LOLR Facilities}

As argued in Section 5.3, the fact that direct usage of the LOLR was relatively low does not imply that the facilities were not extremely important to the viability of the broker-dealers and to their ability to hold and fund risky assets in a time of great market stress. Nevertheless, the actual usage of the TSLF and PDCF are not inconsistent with the model of this paper.

Table 6 and Figure 9 show the maximum usage of the TSLF and PDCF by the various firms, as a fraction of inventory, over the 2nd, 3rd, and 4th quarters of 2008. Lehman Brothers and Merrill Lynch, which were the most challenged, used the facilities more than the other two firms in the 2nd and 3rd quarters. This usage reached about 10\% of inventory in Q3 2008. Morgan Stanley and Goldman Sachs used the facilities sparingly until the quarter following Lehman Brothers' bankruptcy, when usage rose to about 10\% of inventory for Goldman Sachs and almost 30\% of inventory for Morgan Stanley.

Finally, Figure 10 shows that, consistent with the model, higher usage of the facilities is positively associated with higher CDS spreads. In other words, weaker firms rely more heavily on the facilities. 


\section{Exploring policies that mitigage the moral hazard from LOLR}

In a typical financial crisis, the prices of certain assets fall and private market funding for those assets evaporates. Having lost this funding, financial institutions might have to sell assets at depressed prices to pay off their outstanding short-term debt. Furthermore, the collective selling of these assets could trigger a downward spiral in which prices weaken further, margin calls require financial institutions to sell even more of their assets, prices weaken again, etc. ${ }^{12}$ To forestall this eventuality, central banks offer LOLR facilities, which, at least temporarily, enable financial institutions to replace lost private market funding with funding at the central bank. Furthermore, with their immediate funding pressures alleviated, financial institutions can sell assets gradually and in a less disruptive manner, while waiting for market conditions to normalize. The point of this paper, however, is that financial institutions have an incentive to reduce risky asset sales. Put another way, financial institutions with access to an LOLR facility will not just slow the pace of their asset sales to accommodate market illiquidity, but will target a smaller total quantity of sales. We now explore two categories of policy changes to alleviate the moral hazard problem of reduced asset sales. The first category would condition participation in LOLR facilities on leverage reduction or asset sales. This conditioning could take three forms: prevent the most highly-levered financial institutions from accessing LOLR facilities; set a rate of deleveraging as a condition of continued access to LOLR facilities; or set a rate for selling assets funded through LOLR facilities as a condition of continued access. Furthermore, whichever of these three forms is pursued, exclude customer funding from the risk-reduction requirements. The second category of policy changes would use LOLR facilities to encourage institutions with relatively clean balance sheets, i.e., institutions without significant levered positions in troubled assets, to purchase those assets. We assume that this collection of policies takes the systemic benefits of LOLR facilities as given, aiming solely to minimize the associated moral hazard problems.

\subsection{Condition LOLR Participation on Leverage Reduction or Asset Sales}

The most direct mitigant of the moral hazard of reduced deleveraging is to condition LOLR borrowing, in some way, on risk reduction. The risk reduction rule has to be strict enough to offset

\footnotetext{
${ }^{12}$ See, for example, Brunnermeier and Pederson (2009).
} 
the effect described in this paper, but not so strict as to subvert the systemic benefits of the LOLR facility. Requiring that assets funded at the facility be liquidated within a week, for example, would likely result in the very fire sales that the facility had been designed to prevent.

Policy makers have in the past, to a very limited extent, imposed deleveraging condition on LOLR facilities. The Fed's PDCF program, for example, was opened in March 2008 "for a minimum period of six months, which "may be extended as conditions warrant. ${ }^{13}$ Setting a finite term for the program can be viewed as instructing primary dealers to stabilize their balance sheets over that term. The perception that the Fed would extend the program, however, weakened the deleveraging message of setting a program termination date. In fact, the program was extended four times and acceptable collateral was once expanded before the program was terminated in February 2010. Similarly, while the ECB started its LTRO with one-year repo loans, it subsequently supplied two rounds of three-year repo loans and is currently contemplating another round. The theoretical and empirical analysis of this paper can help explore policies aimed at combating the tendency of banks to slow or postpone asset sales and deleveraging. We explore a few specific policies along these lines:

\subsubsection{Prevent the Most Highly-Levered Firms From Accessing LOLR Facilities}

Figure 2 (a) illustrated that a bank with very high leverage would not deleverage at all. Section 5 showed that Lehman Brothers, the investment bank with the highest illiquid inventory leverage, was very slow in deleveraging its worst assets. And Acharya, Fleming, Hrung, and Sarkar (2011) show that the most highly-levered banks use LOLR the most. Therefore, to the extent that providing liquidity to the set of stronger banks is consistent with systemic stability, moral hazard can be mitigated by imposing a leverage threshold over which access to LOLR would be denied. Excluding the banks that are leveraged much more highly than their peers not only reduces the moral hazard of LOLR facility utilization, but also reduces the moral hazard of ex-ante investment decisions. Knowing that being more leveraged than one's peers might mean being barred from future safety nets would constrain risk-taking actions before a bust. Note that these leverage constraints could apply not just at the initiation of the LOLR facility, but over its life. This would mean that a bank might initially qualify for the facility, but then, by allowing its leverage to rise excessively, be

\footnotetext{
${ }^{13}$ Federal Reserve Bank of New York (2008)
} 
barred from future participation.

\subsubsection{Set a Rate of Deleveraging as a Conditon of Access to LOLR Facilities}

The public policy motivation for LOLR facilities is to prevent destabilizing fire sales of assets in response to shortages of liquidity. Maintaining balance sheets at their current levels and protecting banks against losses from asset sales are not typically cited as public policy objectives. Therefore, deleveraging requirements could be set so as as to mitigate the moral hazard problem discussed in this paper without jeopardizing systemic stability. More specifically, central banks might require that illiquid inventory leverage be reduced over some time period by a percentage of the leverage supported through its facilities. Say, for example, that a bank had 100 in illiquid assets and 10 in capital for a leverage of 10 , with 20 of those assets, or 2 leverage points, being funded through the

LOLR facility. Then the central bank might require that the bank reduce leverage by $10 \%$ of those 2 leverage points, or 0.2 , over the following six months.

\subsubsection{Set a Rate for Selling Assets Funded by LOLR as a Conditon of Access}

The previous policy focuses on leverage as a proxy for risk when borrowing through an LOLR facility. In addition, leverage can be reduced not only by asset sales, but by raising capital as well. And, given the policy objective of minimizing disruptive asset sales in a crisis, raising capital should certainly be encouraged as an alternative to outsized asset sales. Leverage, however, is relatively difficult to monitor and can be subject to gaming. With respect to monitoring, many banks compute leverage accurately only at quarter end. With respect to gaming, banks can manipulate various quantities that enter into leverage calculations, e.g., the classification of assets into liquidity buckets, the use of derivatives instead of cash assets, the reduction of assets around reporting dates, etc. An alternative, simpler condition for access to LOLR facilities, therefore, could be a schedule of asset sales. A bank funding $\$ 100$ in illiquid assets at the central bank might, for example, be required to sell $10 \%$ or $\$ 10$ of risky assets over the subsequent six months. This rule can be refined to require sales in each of several broad categories of assets in proportion to LOLR borrowing in each of those categories. 


\subsubsection{Exclude Customer Funding from Risk-Reduction Conditions}

Banks can use access to LOLR facilities to fund both their own positions as well as their customer positions. From a policy perspective, however, it is more important to control LOLR funding of bank positions. First, the moral hazard effect described in this paper is much more relevant to banks' own positions. Should a bank lose funding for its own positions, it suffers losses from premature and suboptimal trade termination and from the market impact of associated fire sales. On the other hand, should a bank lose funding for customer positions, it loses the less profitable (and less risky) fee income from that business line. Second, banks are likely to pose greater systemic risk than the vast majority of their customers. Third, since banks have strong incentives of their own to monitor the risks of loans to customers, the central bank will probably not add much value along those lines. Fourth, there is a public policy interest in maintaining the indirect access that healthy bank customers have to LOLR facilities so that they can purchase some of the distressed assets that banks are selling. For all these reasons then, when banks are required to delever or to sell assets as a condition of obtaining LOLR funding, these requirements should apply to their own rather than their customer accounts. This distinction can be implemented easily as total loans to customers are routinely monitored and reported. Returning to an earlier example, say that a bank is funding $\$ 100$ of assets at the central bank, $\$ 60$ for customers and $\$ 40$ for its own account. Then the central bank might require that $10 \%$ of the $\$ 40$ of assets, or $\$ 4$ of assets, be sold over the next six months.

\subsection{Opening LOLR Facilities to Potential Asset Purchasers}

The examples of this paper with an endogenous asset price show that giving banks access to LOLR facilities can raise the price of the illiquid asset but lower the quantity that banks sell. By contrast, giving the potential purchasers of the asset access to LOLR facilities can raise the price and raise the quantity traded. This outcome dominates from a public policy perspective: the higher price relieves fire-sale pressures and the higher quantity traded reduces risk at the vulnerable and systemically important banks.

In some sense central banks offer potential purchasers indirect access to LOLR facilities through banks that have direct access. But this indirect access depends on the cooperation of banks 
that, particularly during a crisis, have their own agenda. And the anecdotal evidence presented in this paper shows that investment banks cut back on customer funding at the height of the crisis. Therefore, to achieve the better LOLR outcome of higher asset prices and greater quantities traded, central banks would do well to give potential asset purchasers direct access to LOLR facilities.

There were, in fact, two Fed programs during the crisis that provided direct funding to asset purchasers, namely, the Commercial Paper Funding Facility (CPFF) and the Money Market Investor Funding Facility (MMIFF). To the extent that the CPFF was applied to asset-backed commercial paper, these programs were very much motivated by the considerations discussed here. Furthermore, the size of the CPFF was significant, although the MMIFF never did make any loans. Nevertheless, these programs cannot be said to have shifted LOLR from supporting troubled financial institutions to supporting asset purchasers. First, the CPFF bought a lot of commercial paper sold by financial institutions and asset-backed commercial paper sold by conduits, which were largely the creations of traditional financial intermediaries. Second, the simultaneous existence of significant LOLR facilities directed at bank and investment banks, like the bank discount window, the TSLF, and the PDCF, meant that the overall set of LOLR facilities was not particularly designed to encourage troubled financial institutions to sell assets to healthier, potential purchasers of their assets. ${ }^{14}$

The earliest conception of the Troubled Assets Relief Program (TARP) was very much consistent with such logic. More specifically, the original plan for TARP was for the government on its own or in partnership with private entities - to purchase illiquid assets from the market. That this plan was eventually discarded, however, should not be construed to mean that such purchases are impractical. First, Ben Bernanke, Henry Paulson, and others, even before TARP had passed Congress, had shifted their objectives from asset purchases to injecting equity into troubled financial institutions. Second, while the implementation of large-scale asset purchases proved more difficult and time consuming than originally anticipated, all of that planning had to be done as the crisis unfolded. Should the policy of this paper be adopted, the planning could begin much

\footnotetext{
${ }^{14}$ There are some operational hurdles in providing LOLR loans to institutions that do not usually interact with the Fed. But these can be overcome, as they were with the CPFF, by having banks and investment banks act as agents for these loans. See, for example, Adrian, Kimbrough, and Marchioni (2011). Note that this agency model is very different from having banks and investment banks use their own balance sheets to provide indirect LOLR to their customers, which transmission mechanism is not, as discussed earlier, very reliable in a crisis.
} 
earlier. $^{15}$

\section{Conclusion}

In this paper, we examined theoretically and empirically an unintended consequence of LOLR policies: if such policies are not suitably conditioned on borrowers financial health, then they could result in a slow-down of deleveraging by the borrowers and increase their illiquid leverage and risk of default. Several mechanisms to deal with this consequence were explored: provide LOLR financing only to relatively healthier borrowers or condition LOLR terms on their health; condition access to LOLR facilities on a certain quantity of asset sales or financial deleveraging; and, provide LOLR financing to healthy, potential buyers of illiquid assets. There are several directions in which the present work could be extended to enhance understanding of the optimal design of LOLR policies.

First, to design LOLR policy to balance the ex-ante moral hazard and the ex-post spillover containment from financial failures (e.g., due to contagion), it would be useful to model the spillovers. This could help specify a regulatory objective function as the expected output of the system, which is affected by both the greater risk due to the moral hazard effect and the reduced spillover costs from access to LOLR facilities when private funding dries up. It is most likely the case that, in general, moral hazard would have to be contained even if not entirely eliminated as Fischer (1999) observes so that optimal LOLR support may be limited. (Formally, an interior level of "l" would be optimal in the model.) It may also be optimal to combine LOLR policy with macro-prudential supervision and tools such as capital requirements so as to contain the ex-ante risks from LOLR policy.

Second, limited LOLR support might conceivably be achieved through "constructive ambiguity in whether LOLR would be extended or not. Such ambiguity, however, often lacks time consistency and may not be credible. A more pragmatic approach might be to limit the scope of the LOLR, for instance, by restricting it - in an ex-ante and credible manner - to specific collateral types or to borrowers of adequate financial health. This could be seen as the likely intent of the Dodd-Frank Act's restrictions on the Federal Reserve's 13(3) exceptional powers to provide LOLR financing to individual non-banks, like AIG Financial Products, although the results here suggest

\footnotetext{
${ }^{15}$ For an account of the history of TARP, see, for example, Paulson (2010).
} 
that restrictions based on borrower health rather than organizational form would be more efficient.

Finally, if financial firms delever less due to access to LOLR facilities, they might also, over time, become more dependent on these facilities. The recent calls for the ECB to extend its threeyear LTRO, so that troubled banks in Spain and Italy can continue to roll over their holdings of risky sovereign debt, appear to be a case in point. Put another way, it is difficult to unwind large scale LOLR facilities gracefully. This is precisely why this paper argues as does Fischer (1999) that LOLR policy must pay careful attention to the moral hazard consequences of its support of the financial sector.

\section{Appendix A: Proofs}

\section{Proof of Proposition 1:}

From equation (6) in Section 3.2, we have that:

$$
\frac{\partial E}{\partial \alpha}=\frac{1}{\left(e^{I}-\alpha\right)}\left[-E+\left(e^{L}+e^{I} p-B\right)\left(1-G\left(u_{B}\right)+(1-l) x_{2} g\left(u_{B}\right)\right)\right]
$$

In order to proceed, we must first establish the second order necessary condition for a local maximum:

$$
\frac{\partial^{2} E}{\partial \alpha^{2}}<0
$$

Differentiating $\frac{\partial E}{\partial \alpha}$ wrt $\alpha$, we obtain:

$$
\begin{aligned}
\frac{\partial^{2} E}{\partial \alpha^{2}} & =\overbrace{\frac{\left(B-e^{L}-e^{I} p\right)}{<0} \overbrace{\left(e^{L}+e^{I} p-B\right)}^{>0} \overbrace{\left[(1-l) x_{2} g^{\prime}\left(u_{B}\right)-g\left(u_{B}\right)\right]}^{\text {Must be }>0}}^{\underbrace{\left(e^{I}-\alpha\right)^{3}}_{>0}} \\
& \Rightarrow(1-l) x_{2} g^{\prime}\left(u_{B}\right)>g\left(u_{B}\right) \\
& \Leftrightarrow(1-l) x_{2}>\frac{g\left(u_{B}\right)}{g^{\prime}\left(u_{B}\right)}
\end{aligned}
$$

We assume, for the remainder, that the SOC holds. Next, we would like to obtain an expression 
for $\frac{d u_{B}}{d l}$. We know from equation (7) in Section 3.3 that:

$$
\frac{d u_{B}}{d l}=\frac{\partial u_{B}}{\partial l}+\frac{\partial u_{B}}{\partial \alpha} \frac{d \alpha^{*}}{d l}
$$

We obtained that $\frac{\partial u_{B}}{\partial l}<0$ and that $\frac{\partial u_{B}}{\partial \alpha}<0$ by the solvency condition, but we do not know the sign of $\frac{d \alpha^{*}}{d l}$. We do know by the FOC that at the optimal level of $\alpha^{*}$, if we change $l, \frac{\partial E}{\partial \alpha}=0$ must still hold. I.e.,

$$
\frac{\partial^{2} E}{\partial \alpha \partial l}+\frac{\partial^{2} E}{\partial \alpha^{2}} \frac{d \alpha^{*}}{d l}=0
$$

Assuming the SOC holds, $\frac{\partial^{2} E}{\partial \alpha^{2}}<0$. To obtain the sign of $\frac{d \alpha^{*}}{d l}$, therefore, we must sign the expression $\frac{\partial^{2} E}{\partial \alpha \partial l}$.

$$
\frac{\partial^{2} E}{\partial \alpha \partial l}=\frac{\frac{-\partial E}{\partial l}+\left(e^{L}+e^{I} p-B\right)\left[\frac{-\partial u_{B}}{\partial l}\left(g\left(u_{B}\right)-x_{2}(1-l) g^{\prime}\left(u_{B}\right)\right)-x_{2} g\left(u_{B}\right)\right]}{\left(e^{I}-\alpha\right)}
$$

Solving for the partial derivatives within this expression:

$$
\begin{gathered}
\frac{\partial u_{B}}{\partial l}=-x_{2} \text { and } \\
\frac{\partial E}{\partial l}=\left(e^{I}-\alpha\right)\left[x_{2}^{2}(1-l) g\left(u_{B}\right)\right] \\
\Rightarrow \frac{\partial^{2} E}{\partial \alpha \partial l}=\underbrace{-(1-l) x_{2}^{2} g\left(u_{B}\right)}_{>0}+\underbrace{\frac{1}{\left(e^{I}-\alpha\right)}\left(e^{L}+e^{I} p-B\right)}_{<0} \underbrace{\left[x_{2}\left(g\left(u_{B}\right)-x_{2}(1-l) g^{\prime}\left(u_{B}\right)-g\left(u_{B}\right)\right)\right]}_{>0 \text { solvency condition }} \\
\Rightarrow \frac{\partial^{2} E}{\partial \alpha \partial l}<0
\end{gathered}
$$

Substituting in signs yields our result:

$$
\underbrace{\frac{\partial^{2} E}{\partial \alpha \partial l}}_{<0}+\underbrace{\frac{\partial^{2} E}{\partial \alpha^{2}}}_{<0} \underbrace{\frac{d \alpha^{*}}{d l}}_{<0}=0
$$


Proof of Proposition 2: So far, we have:

$$
\frac{d u_{B}}{d l}=\frac{\partial u_{B}}{\partial l}+\frac{\partial u_{B}}{\partial \alpha} \frac{d \alpha^{*}}{d l}=-x_{2}+\frac{B-e^{L}-e^{I} p}{\left(e^{I}-\alpha\right)^{2}} \frac{d \alpha^{*}}{d l}
$$

From the proof of Proposition 1, we can substitute expressions for $\frac{\partial^{2} E}{\partial \alpha^{2}}$ and $\frac{\partial^{2} E}{\partial \alpha \partial l}$ to solve for $\frac{d \alpha^{*}}{d l}$ :

$$
\begin{aligned}
\frac{d \alpha^{*}}{d l} & =\frac{\left(e^{I}-\alpha\right)^{3}(1-l) x_{2}^{2} g\left(u_{B}\right)+\left(e^{I}-\alpha\right)^{2}\left(B-e^{L}-e^{I} p\right)\left(-x_{2}^{2}(1-l) g^{\prime}\left(u_{B}\right)\right)}{-\left(B-e^{L}-e^{I} p\right)^{2}\left((1-l) x_{2} g^{\prime}\left(u_{B}\right)-g\left(u_{B}\right)\right)} \\
\Rightarrow \frac{\partial u_{B}}{\partial \alpha} \frac{d \alpha^{*}}{d l} & =\frac{\left(e^{I}-\alpha\right)(1-l) x_{2}^{2} g\left(u_{B}\right)+\left(B-e^{L}-e^{I} p\right)\left(-x_{2}^{2}(1-l) g^{\prime}\left(u_{B}\right)\right)}{-\left(B-e^{L}-e^{I} p\right)\left((1-l) x_{2} g^{\prime}\left(u_{B}\right)-g\left(u_{B}\right)\right)} \\
\Rightarrow \frac{d u_{B}}{d l} & =-x_{2}+x_{2}\left[\frac{\left(e^{I}-\alpha\right)(1-l) x_{2} g\left(u_{B}\right)+\left(B-e^{L}-e^{I} p\right)\left(-x_{2}(1-l) g^{\prime}\left(u_{B}\right)\right)}{-\left(B-e^{L}-e^{I} p\right)\left((1-l) x_{2} g^{\prime}\left(u_{B}\right)-g\left(u_{B}\right)\right)}\right]
\end{aligned}
$$

Observing the term inside the brackets, we note by the solvency condition that:

$$
\begin{gathered}
\left(e^{I}-\alpha\right)(1-l) x_{2}>\left(B-e^{L}-e^{I} p\right) \\
\Leftrightarrow \quad\left(e^{I}-\alpha\right)(1-l) x_{2} g\left(u_{B}\right)+\left(B-e^{L}-e^{I} p\right)\left(-x_{2}(1-l) g^{\prime}\left(u_{B}\right)\right)> \\
-\left(B-e^{L}-e^{I} p\right)\left((1-l) x_{2} g^{\prime}\left(u_{B}\right)-g\left(u_{B}\right)\right)
\end{gathered}
$$

Thus, unless we are in a corner region in which $\alpha^{*}=0$ and $\frac{d \alpha^{*}}{d l}=0$, we have our result.

\section{Appendix B: Additional Quotations}

\section{B1. Quotations illustrating the focus on the quality of assets on the balance sheet}

During the quarter, we sold a variety of assets, not just the most liquid. We sold $\$ 4.2$ billion of loans, of which $45 \%$ were mezzanine loans and $55 \%$ were senior loans... [W] sold approximately $\$ 3.5$ billion of level 3 assets and also had additional writedowns of approximately $\$ 2$ billion ... however, this reduction will be offset by net transfers in and other activity of approximately $\$ 3.5$ billion.

- Ian Lowitt, CFO, Lehman Brothers, Q2 2008 Earnings Call 
Prashant Bhatia (Citigroup): The gross long CDO exposure was down about $\$ 6$ billion. Can you breakout what drove the decline and the same on the short side that was down by about $\$ 4$ billion?

John Thain (Chairman and CEO, Merrill Lynch): There are sales, but it is mostly markdowns.

- Merrill Lynch, Q2 2008 Earnings Call

We continued to reduce concentrated risk positions including leverage in Real Estate related loans. These asset classes represented $57 \%$ of tangible common equity at year-end down from $85 \%$ in the third quarter and $224 \%$ at year-end 2007. Legacy leverage loan exposure now stands at $\$ 7$ billion, down from $\$ 52$ billion at its peak last year. Our commercial Real Estate portfolio declined by approximately $25 \%$ to $\$ 10.9$ billion in the fourth quarter alone.

- David Viniar, CFO, Goldman Sachs, Q4 2008 Earnings Call

\section{B2. On the Importance of the Existence of LOLR Facilities for Private Funding Markets}

In addition to [our] conservative risk framework, the Federal Reserve's announcement on Sunday has introduced policies that go even further in mitigating our liquidity risk. The Fed has agreed to accept in the PDCF a broad range of collateral... So while our access to funding continues to be quite robust, the Fed's actions greatly diminished the liquidity risk associated with our secured funding book...

[I]t is not like we have assets sitting there that we need to take to the Fed. But I think the Fed being there is really a big statement about liquidity risk. I've seen reports. I've seen articles about tri-party repo is too risky; it is going away. I have never given any of them any weight. But with the Fed doing that it kind of takes away most of that risk - if you thought it was there.

- David Viniar, CFO, Goldman Sachs, Q3 Earnings Call, September 16, 2008

The most difficult to fund non-central bank eligible assets which includes capital commitments and other receivables represents roughly $10 \%$ of our funding needs and had a weighted average 
maturity of greater than 90 days.

- Colm Kelleher, CFO, Morgan Stanley, Q3 Earnings Call, September 16, 2008

\section{B3. Investment Banks Felt Free to Optimize Risk and Return Without Incor- porating the Goals of and the Risks to the Liquidity Facilities}

[The] Federal Reserve's decision to create a lending facility for primary dealers and permit a broad range of investment-grade securities to serve as collateral improves the liquidity picture, and, from my perspective, takes the liquidity issue for the entire industry off the table.

- Dick Fuld, "Wall Street Watches Lehman Walk on Thin Ice," MarketWatch, The Wall Street Journal, March 17, 2008

Meredith Whitney (Oppenheimer): Could you set a market by hitting whatever cash bid there is out there and just get it over with?

John Thain (Chairman and CEO, Merrill Lynch): No, I do not think we want to do dumb things and so we have been balanced in terms of what we sold and at what prices we sold them. We have not simply liquidated stuff at any price we could get. At some point some of the return profiles that people want... you would not want us to sell the assets. We will continue to sell assets but in a way that makes sense from generating returns to our shareholders.

- Merrill Lynch, Q2 2008 Earnings Call, July 17, 2008

Michael Hecht (Bank of America): [S]hould we expect leverage to continue to fall? What... [are] the implications for the type of ROE you guys can earn through this cycle? Are you seeing any pressure here from regulators, rating agencies, investors, to bring leverage down further?

Colm Kelleher (CFO, Morgan Stanley): Well we are obviously in constant touch with a broad array of regulators... what we've been doing is taking down the balance sheet because on a riskadjusted basis, that's what we want to do... So the answer is we're in constant dialogue but we're not getting any pressure in terms of the cycle ROE.

- Morgan Stanley, Q2 2008 Earning Call, June 18, 2008 
We are still placing a significant emphasis on our capital and liquidity to ensure that we have enough dry powder to continue investing in our businesses and to take advantage of attractive risk-adjusted opportunities ...

People cannot gloss over lightly the event that took place in March and the effect that had on the market ... So that is what made us pull down the sails, sail close to shore, preserve our ammunition. We do have excess capital, we do have excess liquidity, we do have leverage if we want to where we can take risk ...

So I'm not saying we're in risk reduction model; we clearly have reduced the risk, we've reduced the balance sheet, we're liquid, we've got capital, we clearly feel we can make money through bear cycles and bull cycles and we're just waiting for the right risk-adjusted opportunity to come along ...

I kind of think we're in the right sort of spot at the moment in terms of giving us the optionality we need to be opportunistic and to be defensive. Obviously we'd like a more normalized market to get rid of some of this legacy portfolio so we can optimize return to the balance sheet. But I think we feel comfortable that we've got optionality sitting where we are at the moment given all the uncertainty around it ...

Some of these [market] prices, frankly, have got to silly and irrational levels so we're going to have the ability to take advantage of that ...

- Colm Kelleher, CFO, Morgan Stanley, Q2 2008 Earnings Call, June 18, 2008

... what we will do with our exposures and our risk will really depend on the opportunities we see in the market ... if we see opportunities we will take advantage of it and increase risk and if we think opportunities are not as good, we'll decrease risk.

- David Viniar, CFO, Goldman Sachs, Q2 Earnings Call, June 17, 2008

Given our significant reduction of legacy assets and our lack of direct consumer exposure, we believe that our balance sheet is strong. Importantly, we have significant capital to take advantage of market opportunities as they arrive in 2009 ... As a result of the broader market dislocation, 
the competitive landscape has changed. Across many of our businesses, trading margins are robust and the premium on risk capital is higher than we've seen in years. In this type of environment return on assets is improving.

- David Viniar, CFO, Goldman Sachs, Q4 Earnings Call, December 16, 2008

Global Markets Financing and Services revenues increased to a record level, up approximately $25 \%$ from the prior-year period, as the firm took advantage of opportunities to both add clients and increase average balances.

- Merrill Lynch, Q2 2008 Press Release, July 17, 2008

Prashant Bhatia (Citigroup): On the prime brokerage side, it looks like ...record revenues even coming off of seasonally strong last quarter, how much of that is share gain versus pricing?

Colm Kelleher (CFO, Morgan Stanley): Pretty much pricing to be honest; not share gain.

- Morgan Stanley, Q3 2008 Earnings Call, September, 16, 2008

[Morgan Stanley was] targeting ... capital to businesses where [it] has leading positions and where the Firm believes it will have better risk-adjusted returns ... engaging in a deliberate and focused reduction of balance sheet-intensive businesses including a resizing of Prime Brokerage, the exit of select Proprietary Trading strategies, the reduction of Principal Investments and the closure of Residential Mortgage Origination.

- Q4 Earnings Press Release, Morgan Stanley, December 17, 2008

Roger Freeman (Barclays Capital): With respect to the balance sheet decline this quarter can you help us think about some of the buckets there?

Colm Kelleher (CFO, Morgan Stanley): Our adjusted leverage has come down as well. So it was broad. It is easier to reduce a matched book which we did but if you think about it in terms of where we are it was pretty broad based. About half the reduction came from a reduction in prime brokerage balances and the rest is pretty much spread out. 
- CFO, Morgan Stanley, Q4 2008 Earnings Call, December, 18, 2008

\section{References}

[1] Acharya, V.V. and D. Backus, 2009, Private Lessons for Public Banking: The Case for Conditionality in LOLR Facilities, Chapter 14, Acharya, V.V. and M. Richardson, eds, Restoring Financial Stability: How to Repair a Failed System, John Wiley \& Sons, March 2009.

[2] Acharya, Viral V., Itamar Drechsler and Philipp Schnabl, 2010, A Pyrrhic Victory? Bank Bailouts and Sovereign Credit Risk, Working Paper, NYU Stern School of Business.

[3] Acharya, Viral V., Itamar Drechsler and Philipp Schnabl, 2012, A Tale of Two Overhangs: The Nexus of Financial Sector and Sovereign Credit Risks, Banque de France Financial Stability Review, (16), April 2012.

[4] Acharya, Viral V., Michael J. Fleming, Warren B. Hrung, Asani Sarkar, 2011, Dealer Financial Conditions and Lender-of-Last Resort Facilities, Working Paper, NYU Stern School of Business.

[5] Acharya, Viral V. and Raghuram Rajan, 2013, Sovereign Debt, Government Myopia and the Financial Sector, Review of Financial Studies, 26(6), 1526-1560.

[6] Acharya, Viral V. and Sascha Steffen, 2012, The "Greatest" Carry Trade Ever? Understanding Eurozone Bank Risks, Working Paper, NYU Stern School of Business.

[7] Acharya, Viral V. and Tanju Yorulmazer, 2008, Cash-in-the-Market Pricing and Optimal Resolution of Bank Failures, Review of Financial Studies, 21(6), 2705-2742.

[8] Adrian, Tobias, Karin Kimbrough, and Dina Marchioni, 2011, The Federal Reserve's Commercial Paper Funding Facility, FRBNY Economic Policy Review, May.

[9] Bagehot, W., 1873, Lombard Street, A Description of the Money Market, Richard D. Irwin Inc.

[10] Brunnermeier, Markus and Pederson, Lasse, 2009, Market Liquidity and Funding Liquidity, Review of Financial Studies, vol. 22(6), pp. 2201-2238. 
[11] Caballero, R.J., Hoshi, T., and Kashyap, A.K., 2008, "Zombie Lending and Depressed Restructuring in Japan," American Economic Review, 98 (5), 19431977.

[12] Adam Copeland, Antoine Martin, and Michael Walker, 2011. Repo runs: evidence from the tri-party repo market, Staff Reports 506, Federal Reserve Bank of New York.

[13] Diamond, D. and R. G. Rajan, 2005, Liquidity Shortages and Banking Crises, Journal of Finance, 60 (2), 615-647.

[14] Diamond, D. and R. G. Rajan, 2011, Fear of Fire Sales, Illiquidity Seeking, and Credit Freezes, Quarterly Journal of Economics (2), 557-591.

[15] Drechsler, I., T Drechsel, D Marques-Ibanez, and P Schnabl, 2013, Who Borrows From the Lender of Last Resort?, Working Paper, NYU Stern School of Business.

[16] Federal Reserve Bank of New York, 2008, Press Release, March 16.

[17] Fischer, Stanley, 1999, On the Need for an International Lender of Last Resort, Speech delivered at the joint luncheon of the American Economic Association and the American Finance Association New York, January 3, 1999, http://www.imf.org/external/np/speeches/1999/010399.HTM

[18] Flannery, M.J., 1996, Financial Crises, Payment System Problems, and Discount Window Lending, Journal of Money, Credit and Banking, 28 (4), 804-24.

[19] Fleming, M.J., 2012, Federal Reserve Liquidity Provision during the Financial Crisis of 20072009, Annual Review of Financial Economics, (4), 161-177.

[20] Gorton, G. and A. Metrick, 2012, Securitized Banking and the Run on Repo, Journal of Financial Economics (104), 425-451.

[21] He, Zhiguo, In Gu Khang and Arvind Krishnamurthy. 2010. Balance Sheet Adjustments in the 2008 Crisis, IMF Economic Review (58), 118-156.

[22] Krishnamurthy, A., Nagel, S. and D. Orlov, 2011, Sizing up Repo, Journal of Finance, forthcoming. 
[23] Paulson, Henry, 2010, On the Brink, Hachette Book Group, New York.

[24] Philippon, T. and V. Skreta, 2012, Optimal Interventions in Markets with Adverse Selection, American Economic Review, (102), 1, 1-28. 


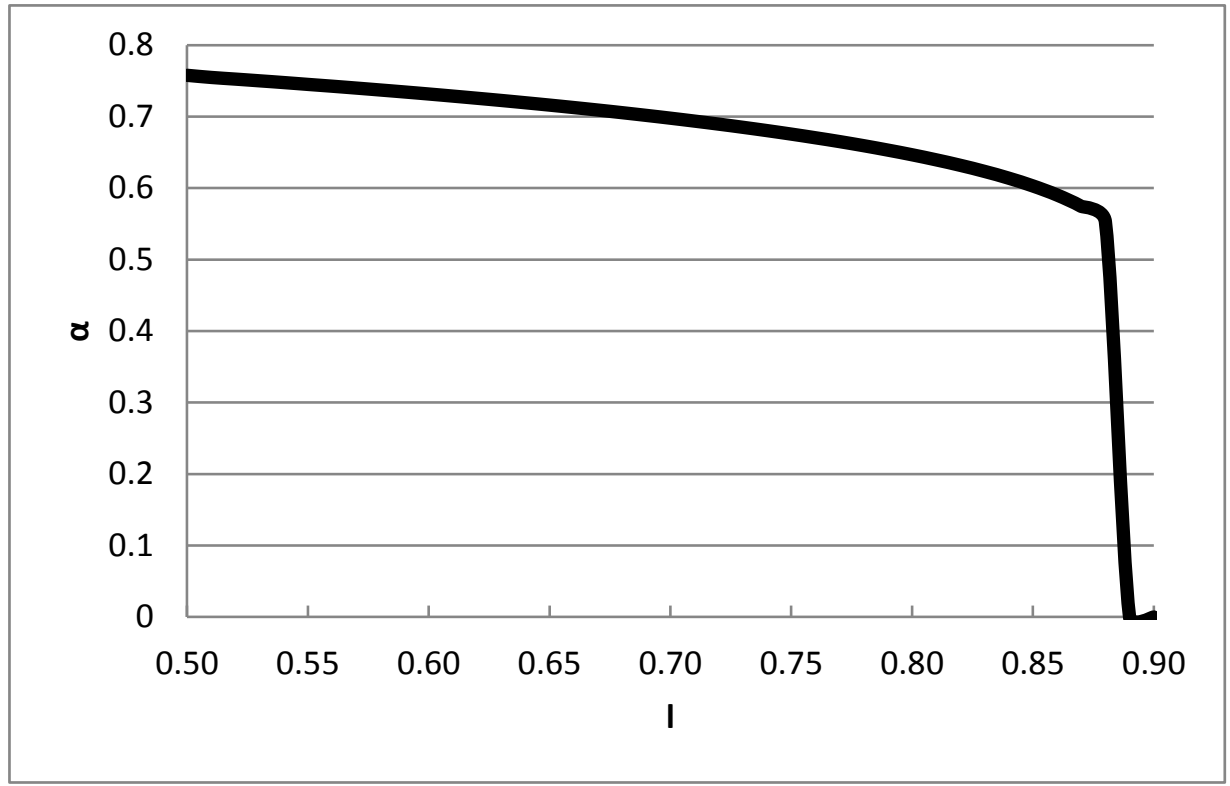

(a) Banks Sales of the Illiquid Asset, $\alpha$, as a Function of $l$

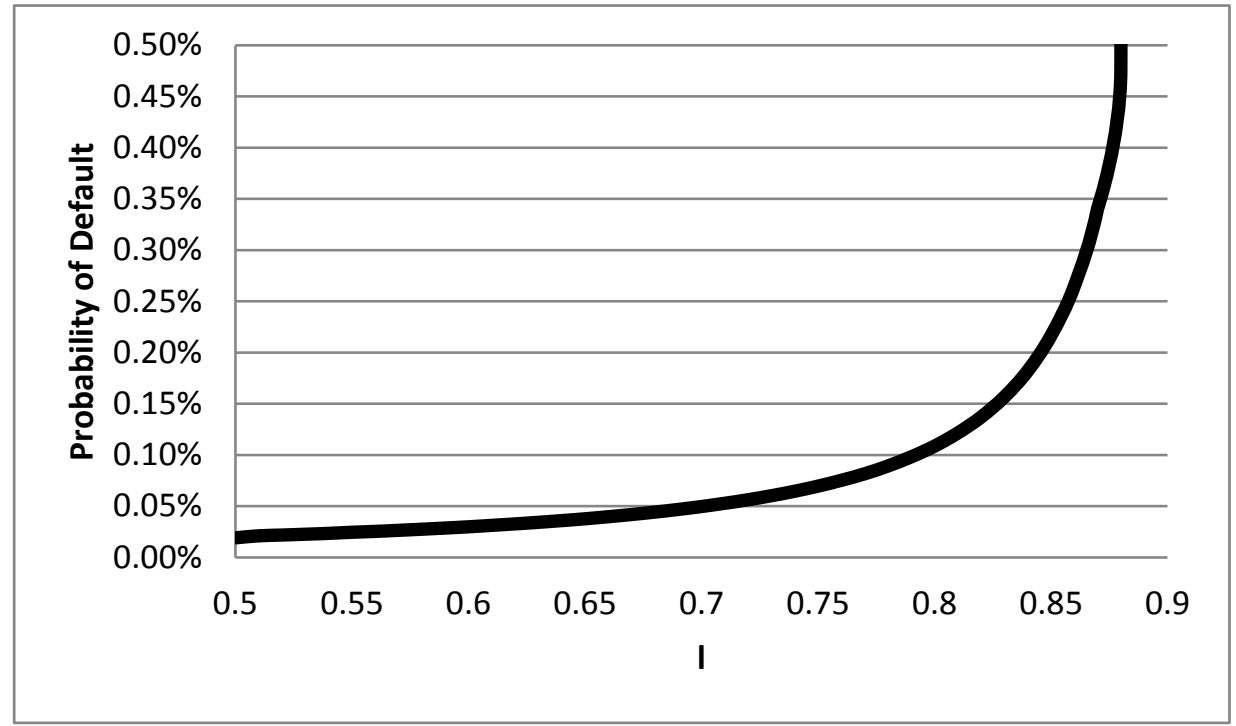

(b) Bank Probability of Default as a Function of $l$

Figures 1 (a)-(b): Bank Deleveraging and Probability of Default as a Function of the Advance Rate of the LOLR Facility, $l$, with the Illiquid Asset Price Determined Exogenously 


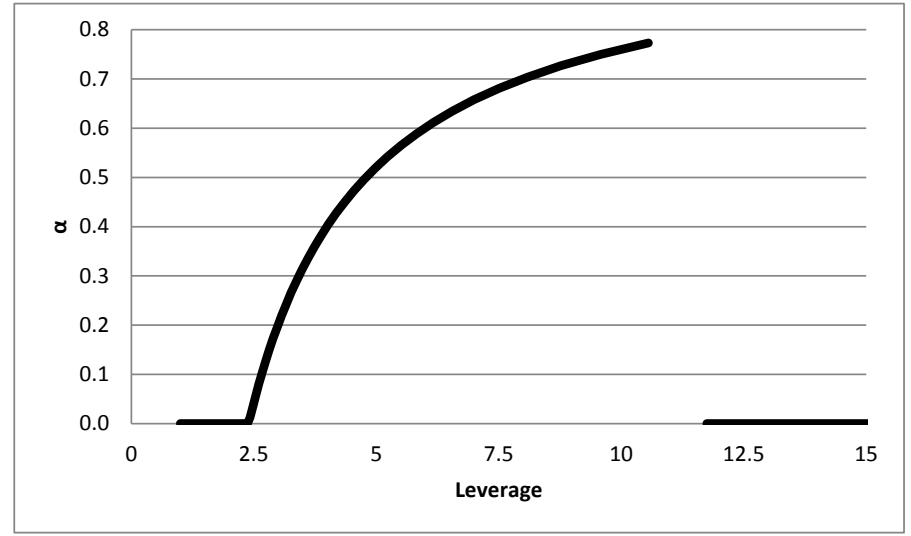

(a) Banks Sales of the Illiquid Asset, $\alpha$, as a Function of Leverage

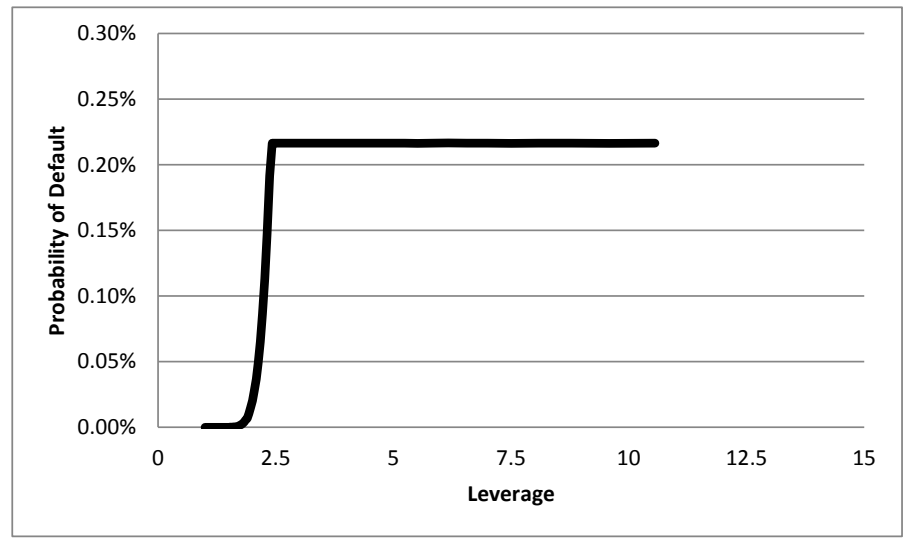

(b) Bank Probability of Default as a Function of Leverage (Truncated Vertical Axis)

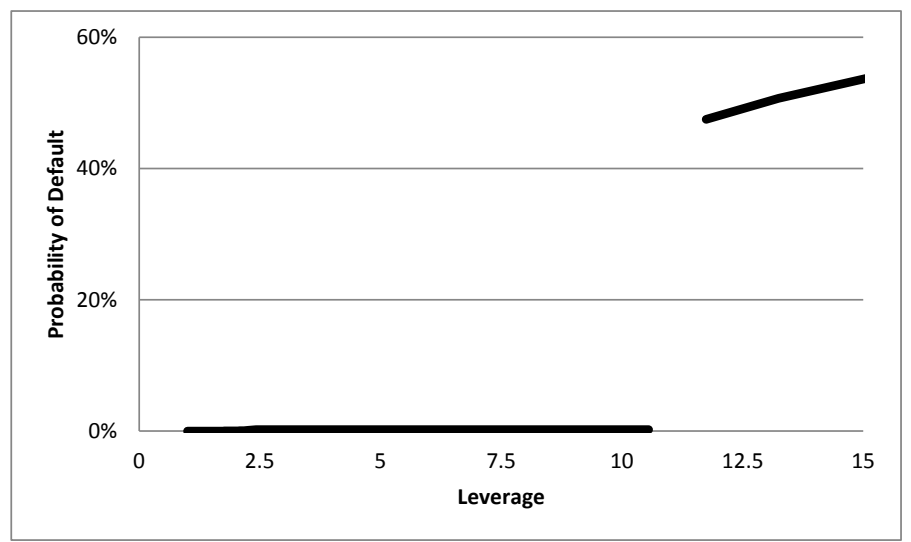

(c) Bank Probability of Default as a Function of Leverage (Full Vertical Axis)

Figures 2 (a)-(c): Bank Deleveraging and Probability of Default as a Function of Leverage, with the Illiquid Asset Price Determined Exogenously 


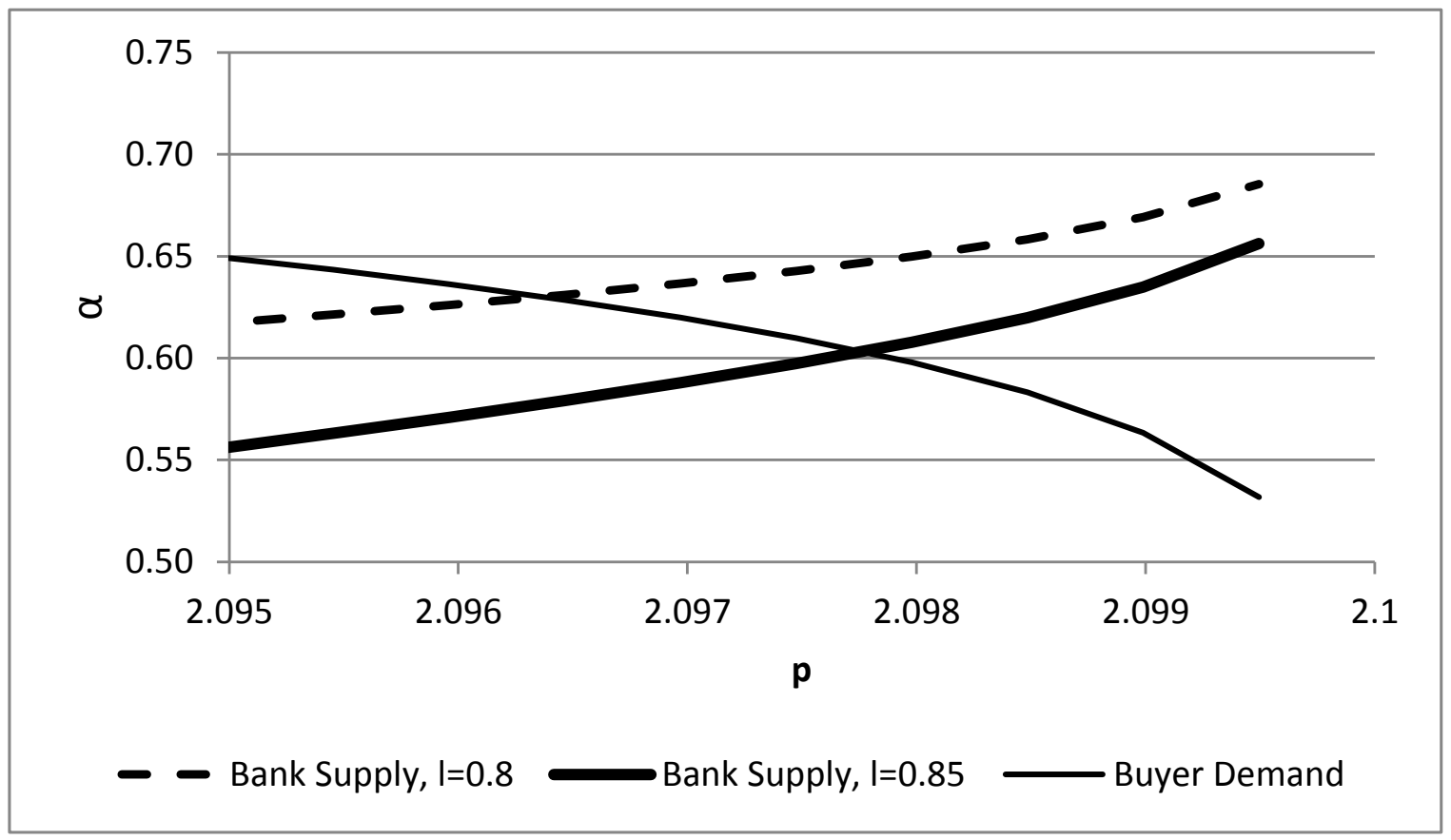

Figure 3: The Endogenous Determination of the Illiquid Asset Price and Quantity Traded. Bank Supply and Buyer Demand of the Illiquid Asset, $\alpha$, as a Function of the Price of the Illiquid Asset, $p$, for Two Advance Rates of the LOLR Facility Available to Banks, $l$ 


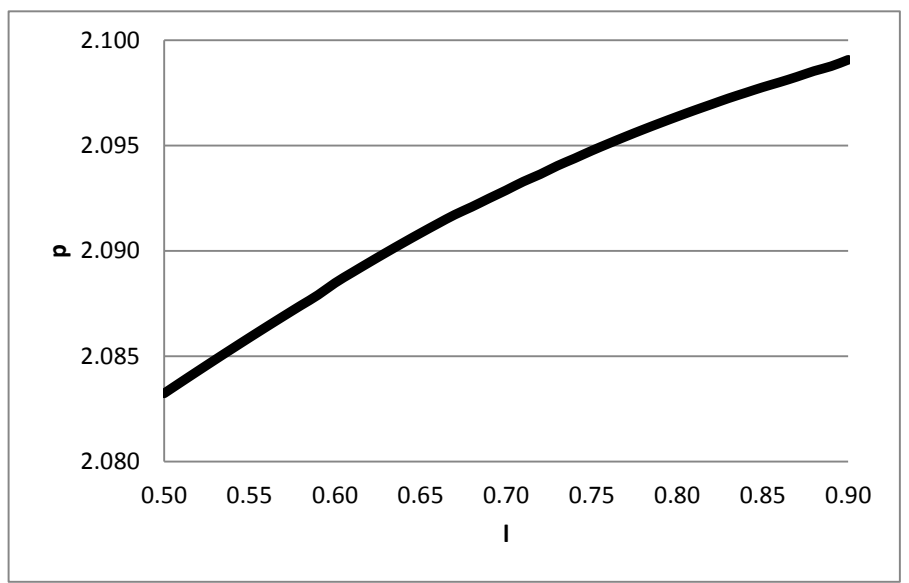

(a) The Equilibrium Illiquid Asset Price, $p$, as a Function of the LOLR Facility Advance Rate Available to Banks, $l$

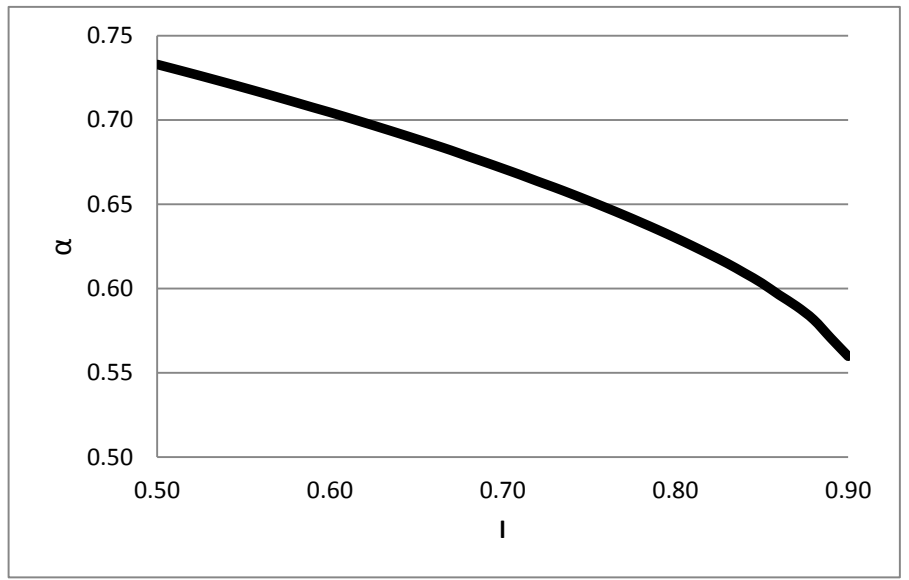

(b) The Equilibrium Quantity Traded of the Illiquid Asset, $\alpha$, as a Function of the LOLR Facility Advance Rate Available to Banks, $l$

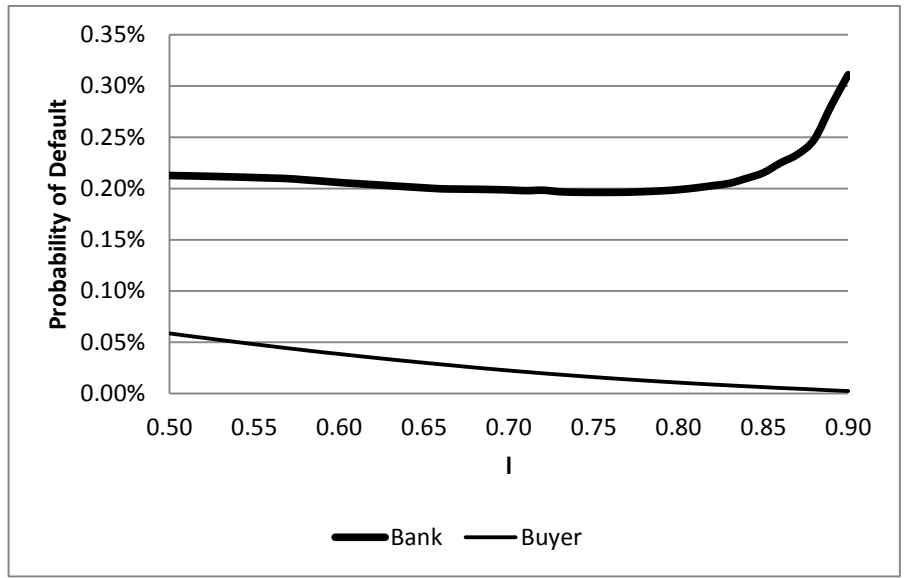

(c) The Probability of Bank and Buyer Default as a Function of the LOLR Facility Advance Rate Available to Banks, $l$

Figures 4 (a)-(c): The Effect of the LOLR Facility Advance Rate Available to Banks, $l$, on the Equilibrium Illiquid Asset Price, $p$, the Equilibrium Quantity Traded of the Illiquid Asset, $\alpha$, and the Bank and Buyer Probabilities of Default 


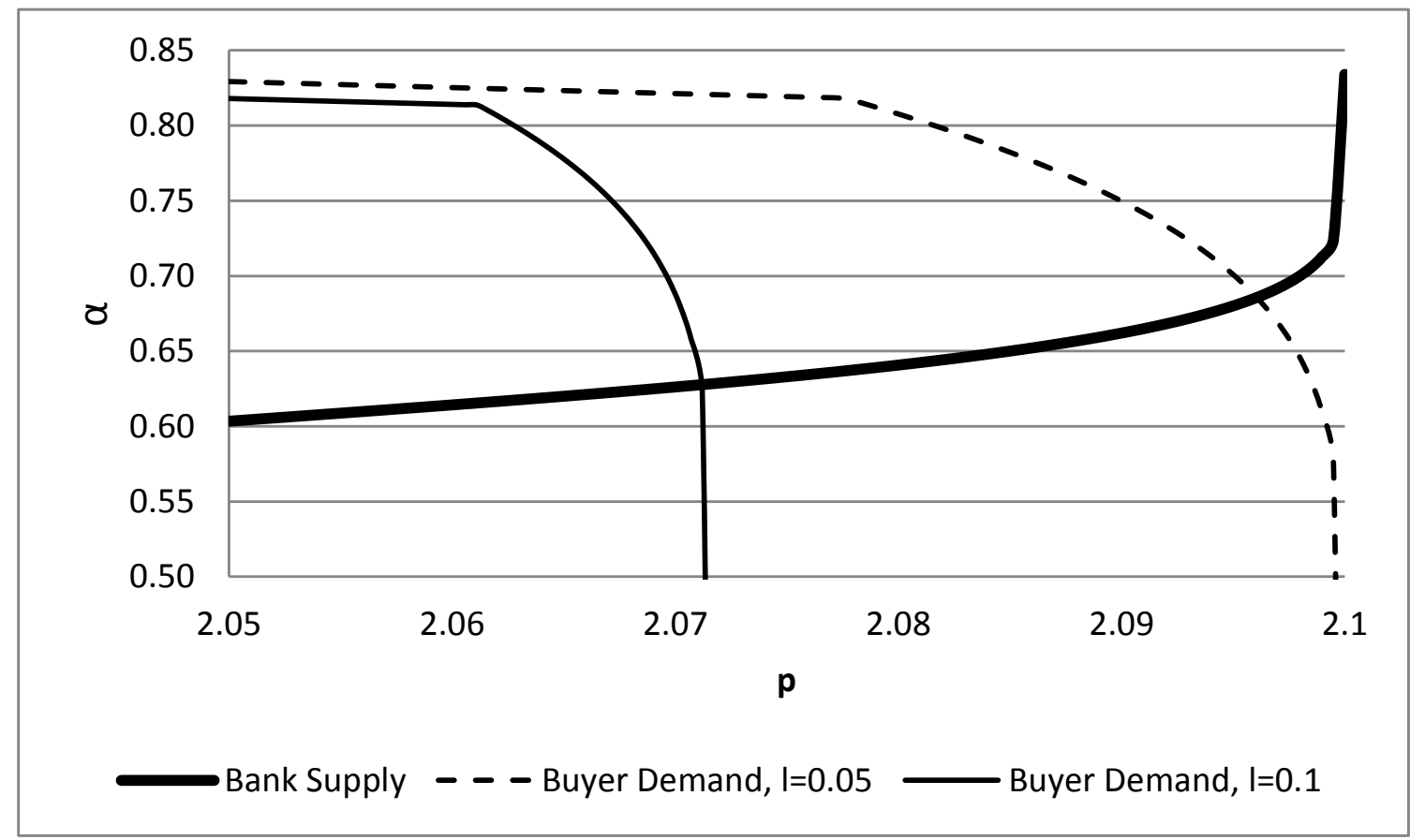

Figure 5: The Endogenous Determination of the Illiquid Asset Price and Amount Traded. Bank Supply and Buyer Demand of the Illiquid Asset, $\alpha$, as a Function of the Price of the Illiquid Asset, $p$, for Two Advance Rates of the LOLR Facility Available to Buyers, $l$ 


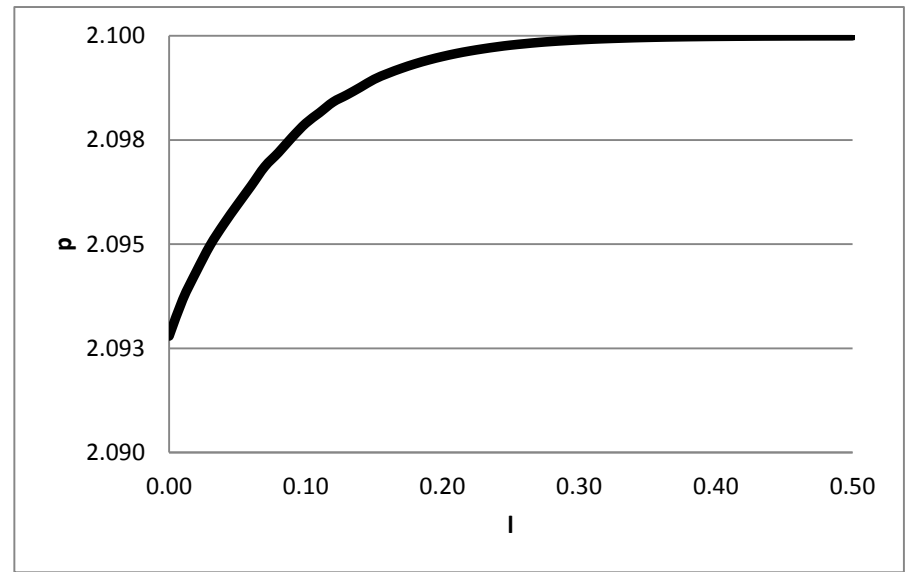

(a) The Equilibrium Illiquid Asset Price, $p$, as a Function of the LOLR Facility Advance Rate Available to Buyers, $l$

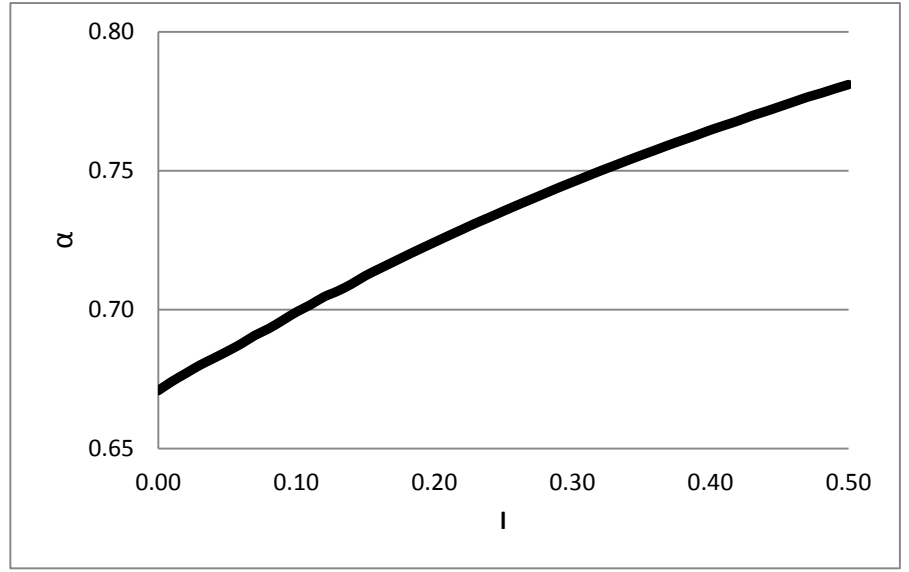

(b) The Equilibrium Quantity Traded of the Illiquid Asset, $\alpha$, as a Function of the LOLR Facility Advance Rate Available to Buyers, $l$

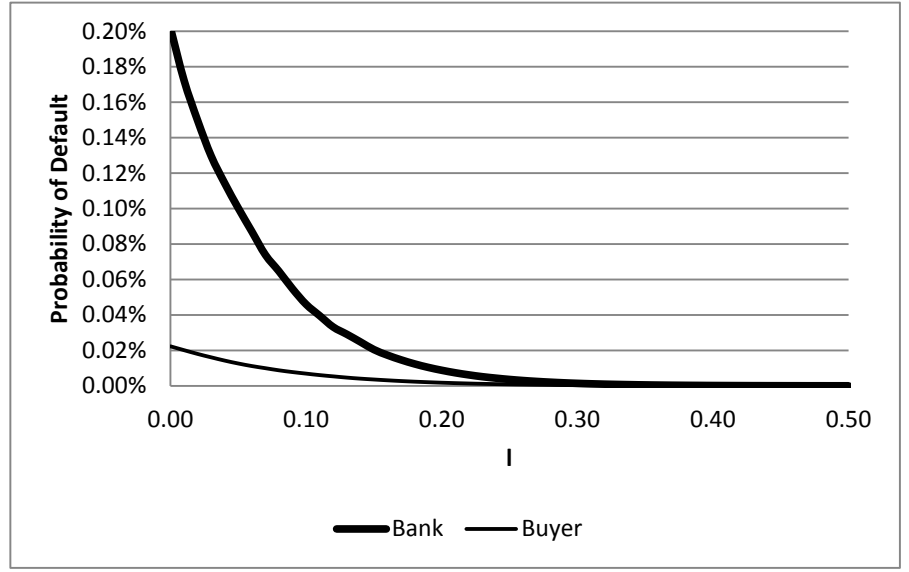

(c) Insert subaption 6c here

Figures 6 (a)-(c): The Effect of the LOLR Facility Advance Rate Available to Buyers, $l$, on the Equilibrium Illiquid Asset Price, $p$, the Equilibrium Quantity Traded of the Illiquid Asset, $\alpha$, and the Bank and Buyer Probabilities of Default 


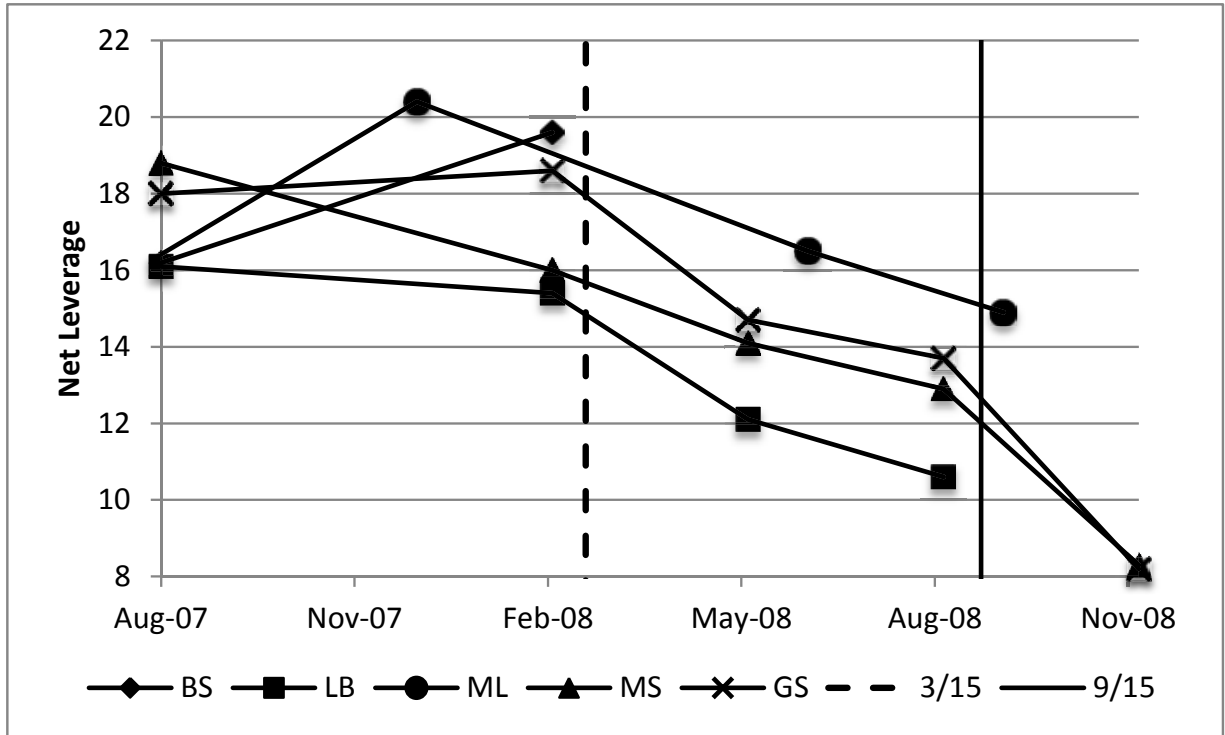

(a) Net Leverage of U.S. Broker Dealers

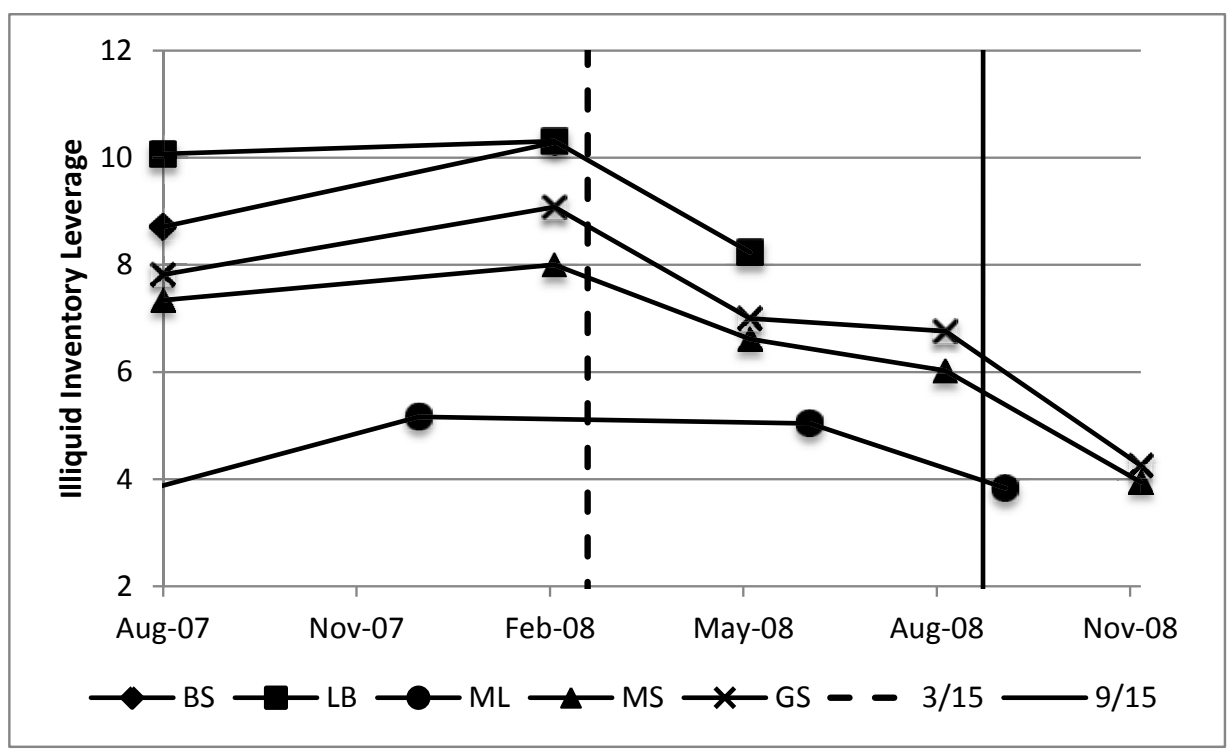

(b) Illiquid Inventory Leverage of U.S. Broker-Dealers

Figures 7 (a)-(b): Leverage of U.S. Broker-Dealers Over the Financial Crisis 


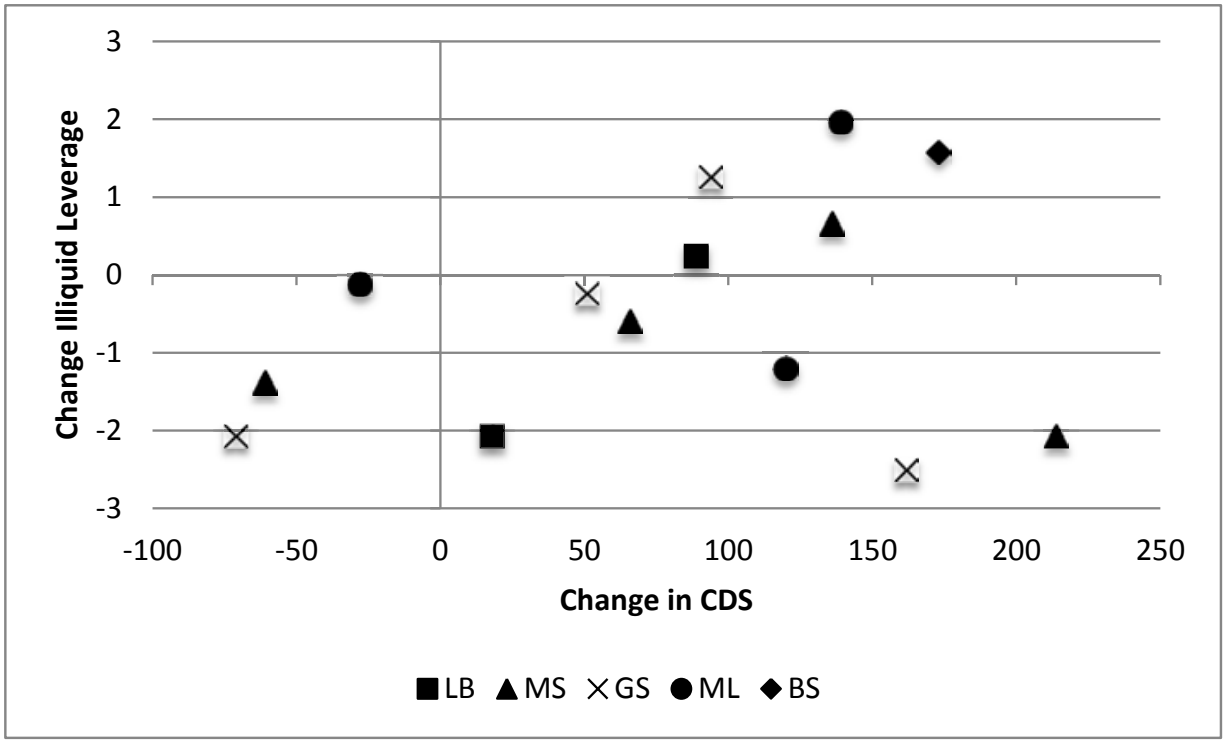

(a) Change in Illiquid Inventory Leverage vs. Change in CDS Spread for U.S. Broker Dealers, by Broker-Dealer

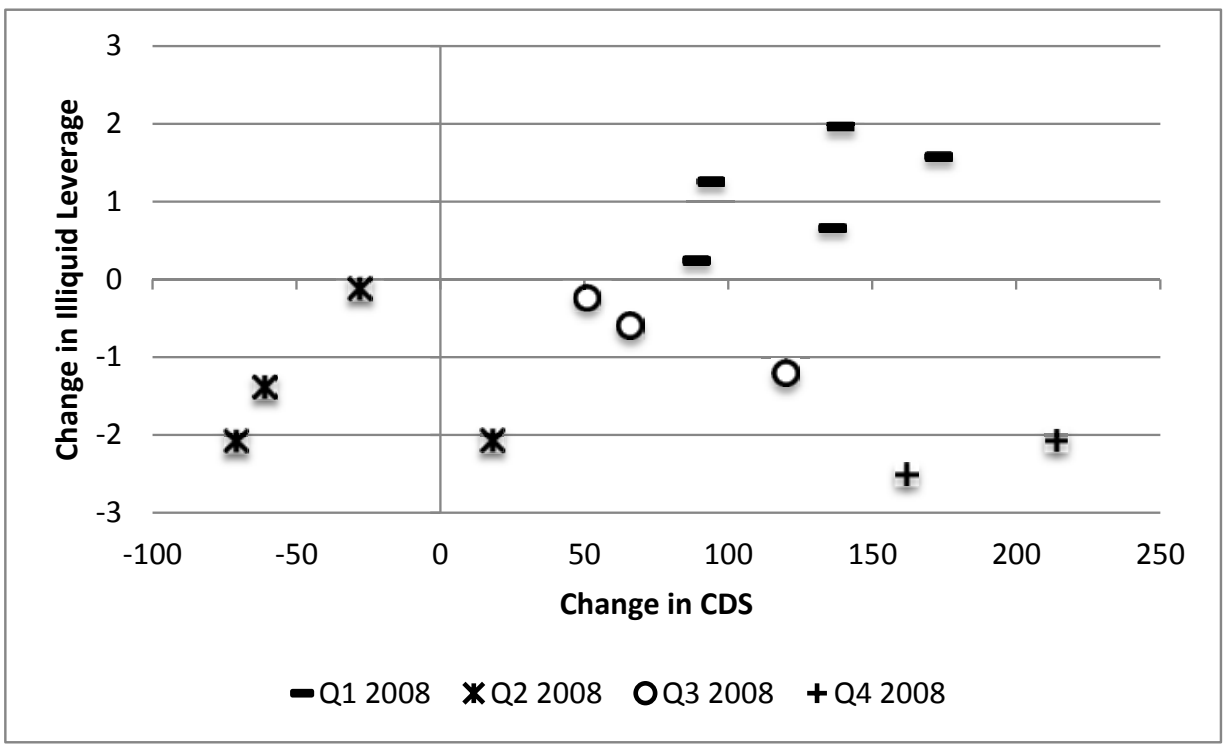

(b) Change in Illiquid Inventory Leverage vs. Change in CDS Spread for U.S. Broker Dealers, By Quarter

Figures 8 (a)-(b): Change in Illiquid Inventory Leverage vs. Change in CDS Spread for U.S. Broker Dealers 


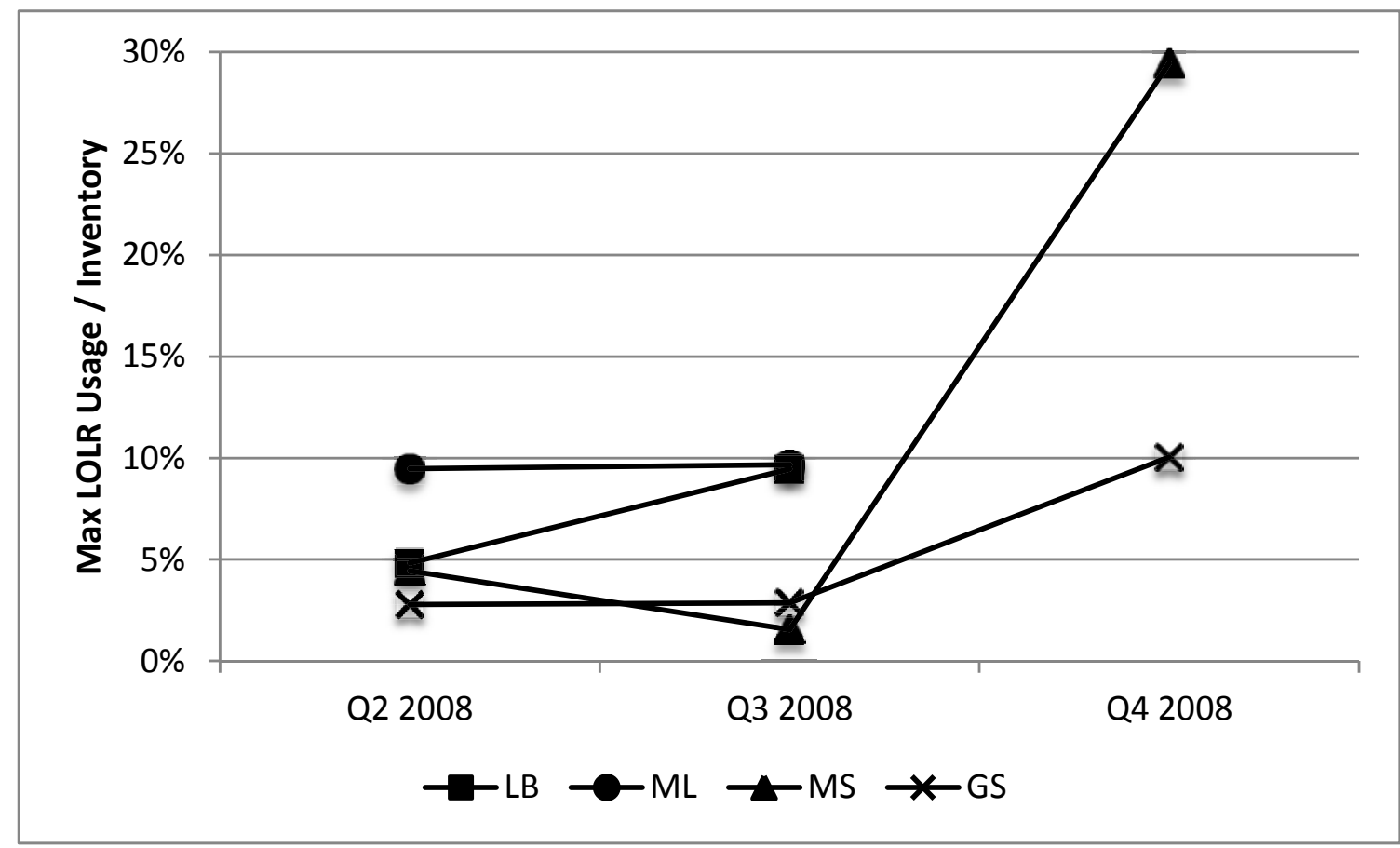

Figure 9: Maximum Combined Usage of TSLF and PDCF as a \% of Inventory, by Quarter

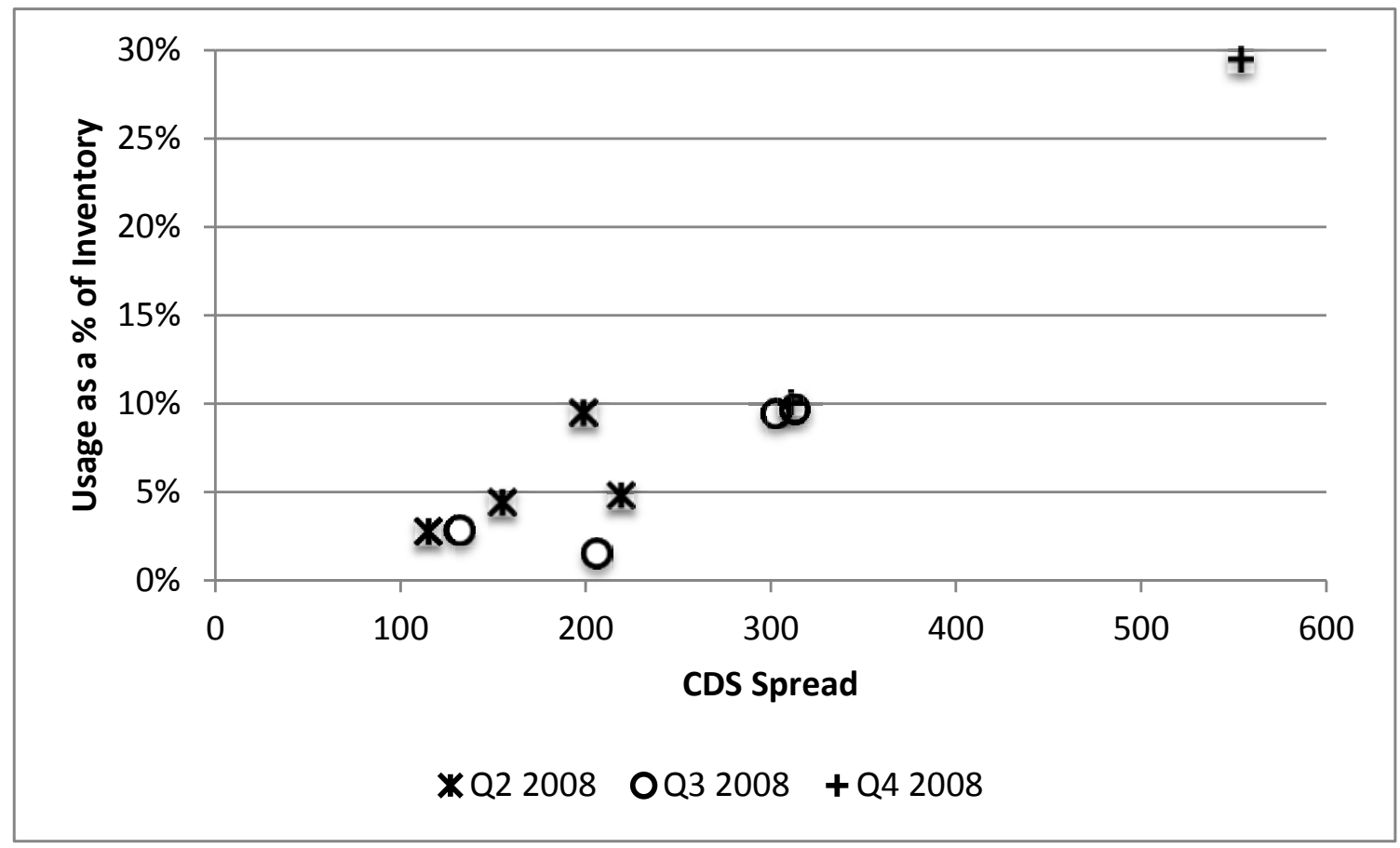

Figure 10: Maximum Combined Usage of TSLF and PDCF as a \% of Inventory vs. CDS Spread 
Table 1: Bank Cash Flows for a Given Choice of $\alpha$ and No Date-1 Default No date-1 default: $e^{L}+p \alpha+\left(e^{I}-\alpha\right) x_{1}+\left(e^{I}-\alpha\right) l x_{2} \geq B$

\begin{tabular}{|c|c|c|c|c|c|}
\hline Date & Liquid Asset & Illiquid Asset & $\begin{array}{c}\text { Illiquid Asset } \\
\text { Cash Flows }\end{array}$ & $\begin{array}{c}\text { LOLR } \\
\text { Cash Flows }\end{array}$ & $\begin{array}{c}\text { Debt } \\
\text { Payment }\end{array}$ \\
\hline Start 0 & $e^{L}$ & $e^{I}$ & & & \\
\hline End 0 & $e^{L}+p \alpha$ & $e^{I}-\alpha$ & & & \\
\hline 1 & $\begin{array}{c}e^{L}+p \alpha-B+\left(e^{I}-\alpha\right) x_{1} \\
+\left(e^{I}-\alpha\right) l x_{2}\end{array}$ & $e^{I}-\alpha$ & $\left(e^{I}-\alpha\right) x_{1}$ & $\left(e^{I}-\alpha\right) l x_{2}$ & B \\
\hline 2 & $\begin{array}{c}e^{L}+p \alpha-B+\left(e^{I}-\alpha\right) x_{1} \\
+\left(e^{I}-\alpha\right) x_{2}\end{array}$ & $e^{I}-\alpha$ & $\left(e^{I}-\alpha\right) x_{2}$ & $-\left(e^{I}-\alpha\right) l x_{2}$ & \\
\hline
\end{tabular}

Table 2: Buyer Cash Flows for a Given Choice of $\alpha^{\text {Buyer }}$ and No Date-1 Default

No date-1 default: $e^{L, \text { Buyer }}-p \alpha^{\text {Buyer }}+\left(e^{I, \text { Buyer }}-\alpha^{\text {Buyer }}\right) x_{1}+\left(e^{I, \text { Buyer }}-\alpha^{\text {Buyer }}\right) l^{\text {Buyer }} x_{2} \geq B^{\text {Buyer }}$

\begin{tabular}{|c|c|c|c|c|c|}
\hline Date & Liquid Asset & Illiquid Asset & $\begin{array}{l}\text { Illiquid Asset } \\
\text { Cash Flows }\end{array}$ & $\begin{array}{c}\text { LOLR } \\
\text { Cash Flows }\end{array}$ & $\begin{array}{c}\text { Debt } \\
\text { Payment }\end{array}$ \\
\hline Start 0 & $e^{L, \text { Buyer }}$ & $e^{I, \text { Buyer }}$ & & & \\
\hline End 0 & $e^{L, \text { Buyer }}-p \alpha^{\text {Buyer }}$ & $\begin{array}{l}e^{I, \text { Buyer }} \\
+\alpha^{\text {Buyer }}\end{array}$ & & & \\
\hline 1 & $\begin{array}{l}e^{L, \text { Buyer }}-p \alpha^{\text {Buyer }}-B^{\text {Buyer }} \\
\quad+\left(e^{I, \text { Buyer }}+\alpha^{\text {Buyer }}\right) x_{1} \\
+\left(e^{I, \text { Buyer }}+\alpha^{\text {Buyer }}\right) l^{\text {Buyer }} x_{2}\end{array}$ & $\begin{array}{l}e^{I, \text { Buyer }} \\
+\alpha^{\text {Buyer }}\end{array}$ & $\begin{array}{c}\left(e^{I, \text { Buyer }}\right. \\
\left.+\alpha^{\text {Buyer }}\right) x_{1}\end{array}$ & $\begin{array}{c}\left(e^{I, \text { Buyer }}\right. \\
\left.+\alpha^{\text {Buyer }}\right) l^{\text {Buyer }} x_{2}\end{array}$ & $B^{\text {Buyer }}$ \\
\hline 2 & $\begin{array}{l}e^{L, \text { Buyer }}-\alpha^{\text {Buyer }}-B^{\text {Buyer }} \\
\quad+\left(e^{I, \text { Buyer }}+\alpha^{\text {Buyer }}\right) x_{1} \\
\quad+\left(e^{I, \text { Buyer }}+\alpha^{\text {Buyer }}\right) x_{2}\end{array}$ & $\begin{array}{l}e^{I, \text { Buyer }} \\
+\alpha^{\text {Buyer }}\end{array}$ & 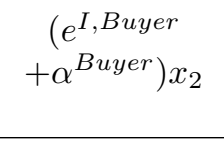 & $\begin{array}{c}-\left(e^{I, B u y e r}\right. \\
\left.+\alpha^{\text {Buyer }}\right) l^{\text {Buyer }} x_{2}\end{array}$ & \\
\hline
\end{tabular}


Table 3: Simplified Balance Sheet for Morgan Stanley as of 2/29/08 (in \$ millions)

\begin{tabular}{|c|c|c|c|}
\hline \multicolumn{4}{|c|}{ Panel A: Reported Balance Sheet } \\
\hline \multirow[t]{2}{*}{ Assets } & $1,090,896$ & Liabilities and Equity & $1,090,896$ \\
\hline & & Total Liabilities & $1,057,616$ \\
\hline Collateralized Agreements & 386,792 & Collateralized Agreements & 288,135 \\
\hline Financial Instruments Owned & 445,837 & Shorts & 171,111 \\
\hline Goodwill and Intangibles & 4,061 & Junior Subordinated Notes & 10,621 \\
\hline \multirow[t]{2}{*}{ Other assets } & 254,206 & Other Borrowings & 587,749 \\
\hline & & Total Equity & 33,280 \\
\hline \multicolumn{4}{|c|}{ Panel B: Conceptual Balance Sheet for Leverage Calculations } \\
\hline Assets & $1,090,896$ & Liabilities and Equity & $1,090,896$ \\
\hline "Gross" Assets & 453,734 & Liabilities & $1,057,616$ \\
\hline Collateralized Agreements & 215,681 & Collateralized Agreements & 215,681 \\
\hline $\begin{array}{l}\text { (Matched Book Lending) } \\
\text { Goodwill and Intangibles }\end{array}$ & 4.061 & (Matched Book Borrowing) & \\
\hline Other Gross Assets & $\begin{array}{r}4,001 \\
233,992\end{array}$ & & \\
\hline Net Assets & 637,162 & & \\
\hline Collateralized Agreements (Short- & 171,111 & & \\
\hline Sale Covering) & & Shorts & 171,111 \\
\hline Financial Instruments Owned & 445,837 & Collateralized Agreements & 72,454 \\
\hline Level I Assets & 126,958 & (Funding) & \\
\hline Level II and Level III Assets & 318,879 & Junior Subordinated Notes & 10,621 \\
\hline \multirow[t]{2}{*}{ Other Net Assets } & 20,214 & Other Borrowings & 587,749 \\
\hline & & Total Equity & 33,280 \\
\hline \multicolumn{4}{|c|}{ Panel C: Leverage Calculations } \\
\hline \multirow{6}{*}{\multicolumn{3}{|c|}{$\begin{array}{l}\text { Tangible Equity Capital }=\text { Equity }+ \text { Junior Subordinated Notes } \\
\quad \text { - Goodwill and Intangibles } \\
\text { Market Capitalization }=\text { Number of Shares Outstanding * Price per Share } \\
\text { Gross Leverage = Assets / Total Equity } \\
\text { Net Leverage = Net Assets / Tangible Equity Capital } \\
\text { Illiquid Inventory Leverage = Level II and Level III Assets / Tangible Equity Capital } \\
\text { Quasi-Market Leverage }=\text { [ (Book) Liabilities }+ \text { Mkt Cap ] / Market Cap }\end{array}$}} & 39,840 \\
\hline & & & 46,555 \\
\hline & & & 32.8 \\
\hline & & & 16.0 \\
\hline & & & 9.6 \\
\hline & & & 23.7 \\
\hline
\end{tabular}




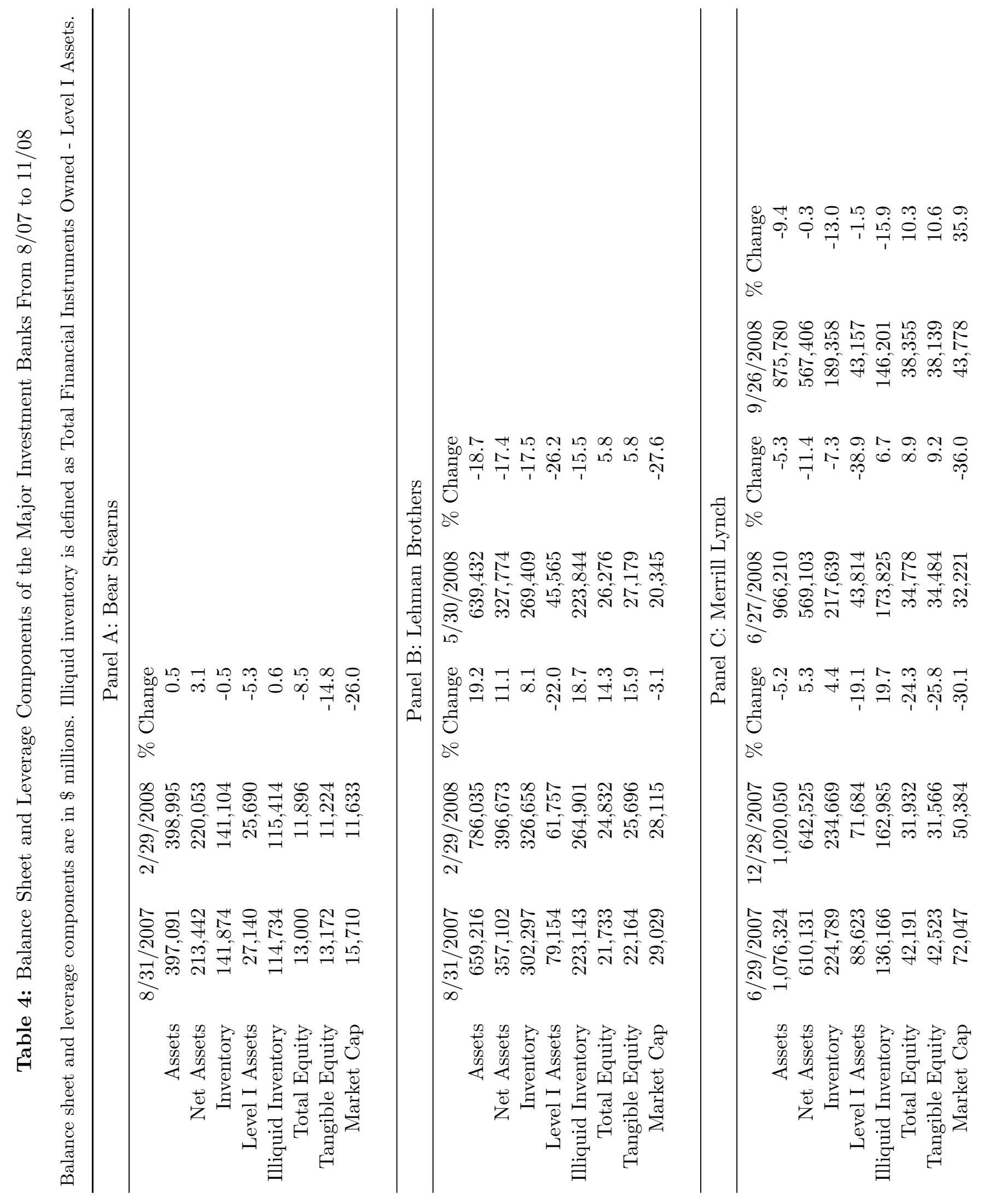




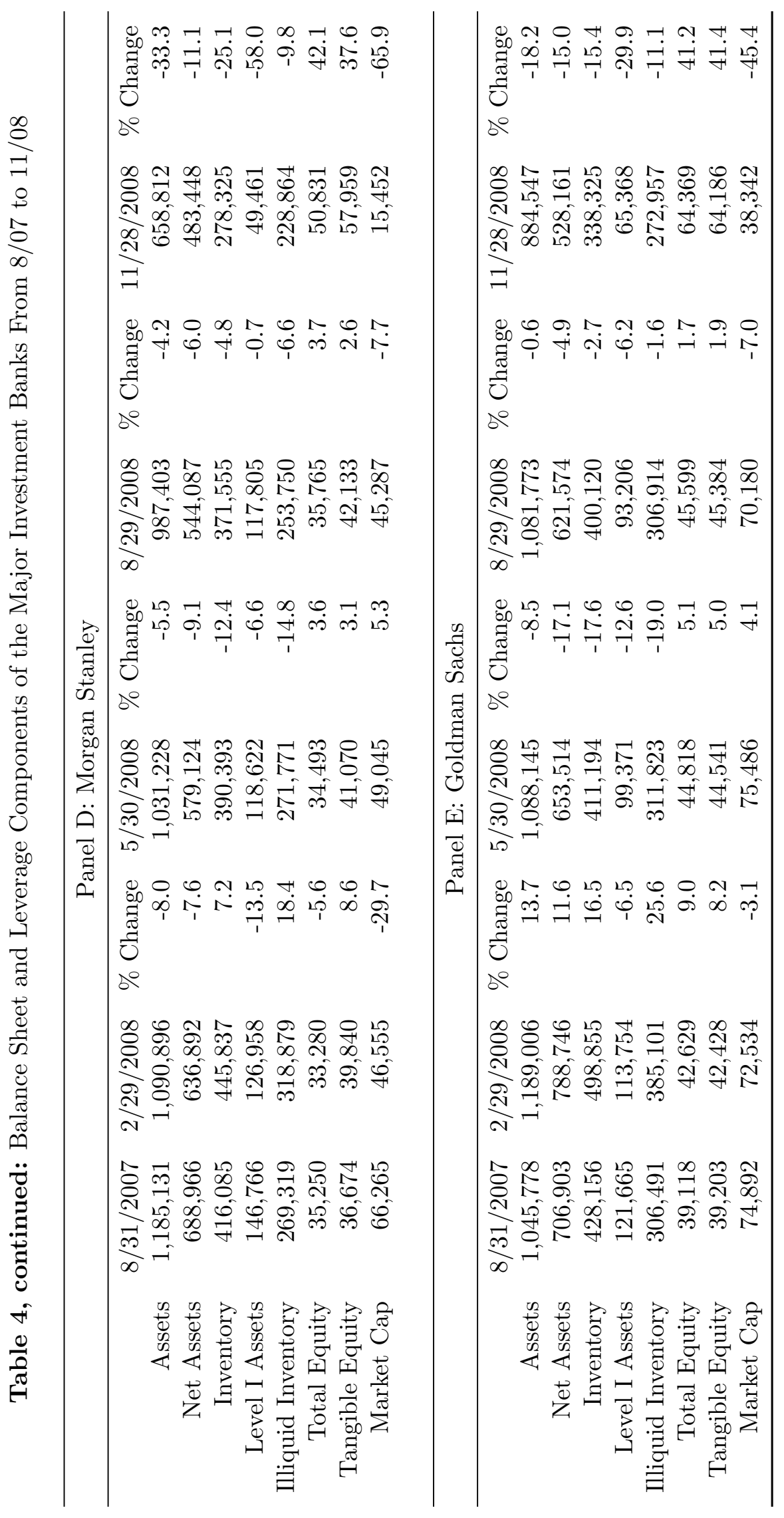




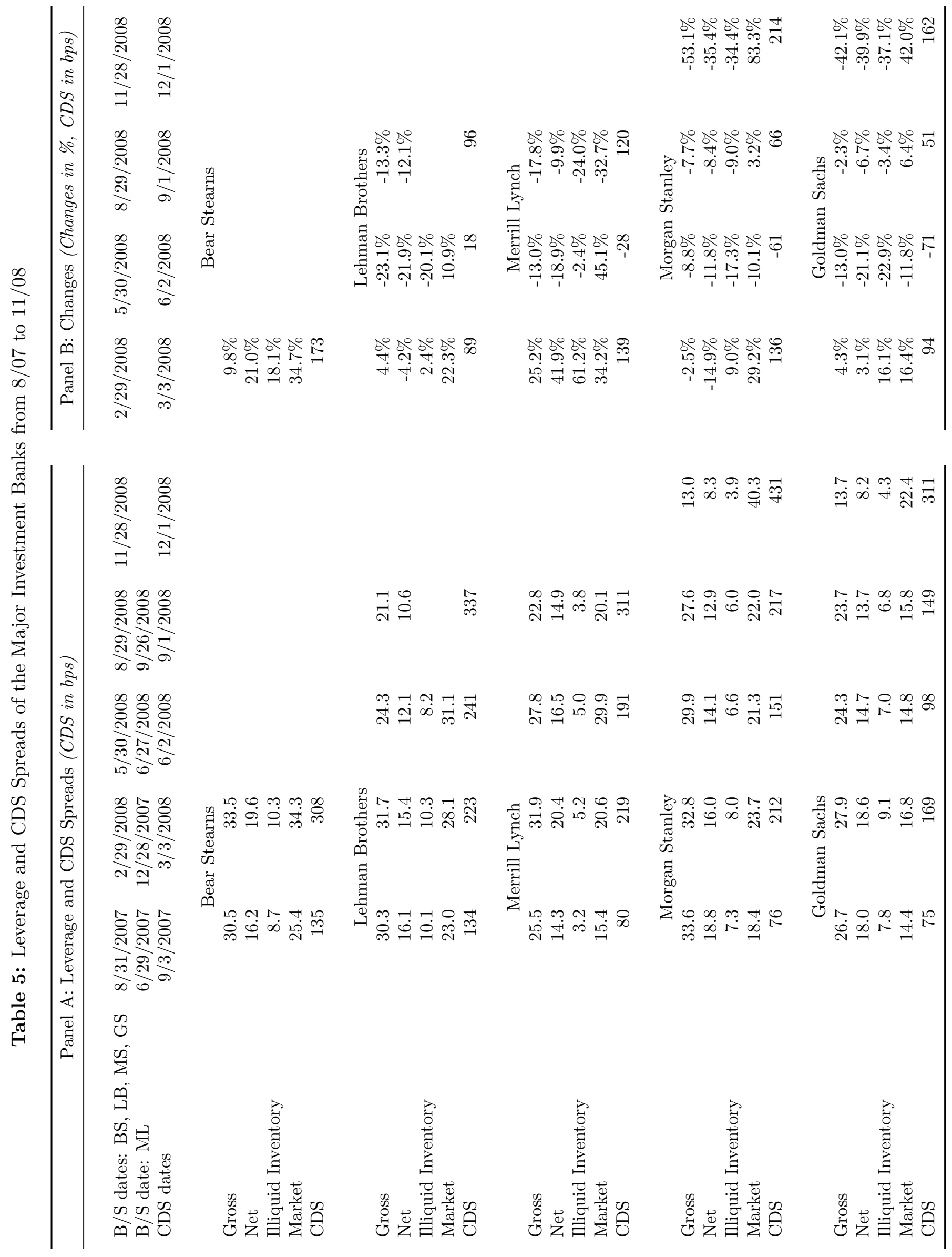




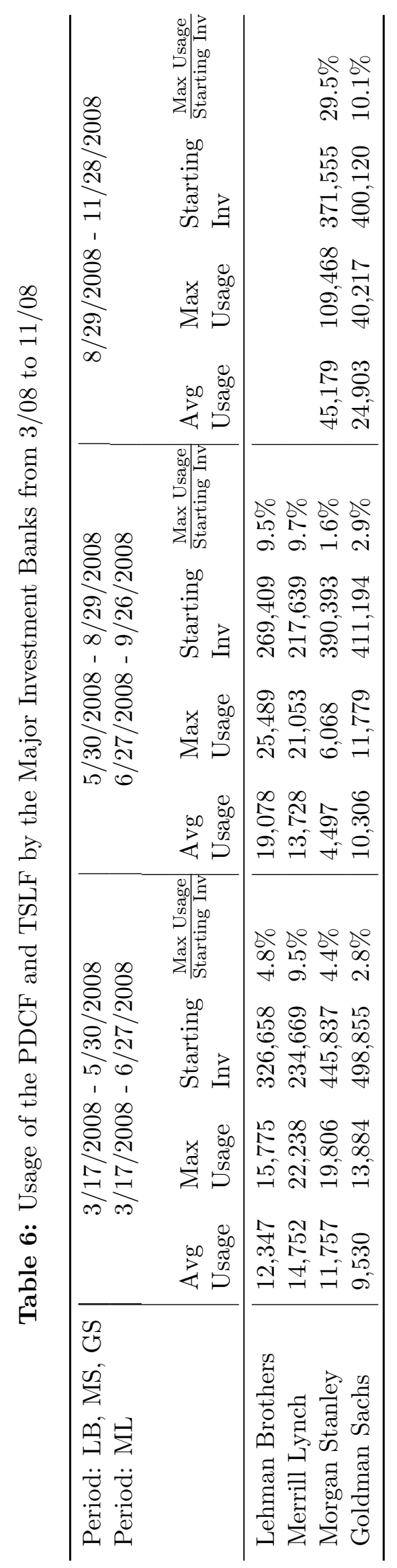

